\title{
The Holocene sedimentary record of cyanobacterial glycolipids in the Baltic Sea: an evaluation of their application as tracers of past nitrogen fixation
}

\author{
Martina Sollai $^{1}$, Ellen C. Hopmans ${ }^{1}$, Nicole J. Bale ${ }^{1}$, Anchelique Mets ${ }^{1}$, Lisa Warden ${ }^{1}$, Matthias Moros ${ }^{2}$, and \\ Jaap S. Sinninghe Damsté ${ }^{1,3}$ \\ ${ }^{1}$ NIOZ Royal Netherlands Institute for Sea Research, Department of Marine Microbiology and Biogeochemistry, \\ and Utrecht University, P.O. Box 59, 179AB Den Burg, Texel, the Netherlands \\ ${ }^{2}$ Department of Marine Geology, Leibniz Institute for Baltic Sea Research (IOW), Warnemünde, Germany \\ ${ }^{3}$ Department of Earth Sciences, Faculty of Geosciences, University of Utrecht, P.O. Box 80.021, \\ 3508 TA Utrecht, the Netherlands
}

Correspondence: Jaap Sinninghe Damsté (jaap.damste@nioz.nl)

Received: 25 July 2017 - Discussion started: 24 August 2017

Revised: 13 November 2017 - Accepted: 22 November 2017 - Published: 22 December 2017

\begin{abstract}
Heterocyst glycolipids (HGs) are lipids exclusively produced by heterocystous dinitrogen-fixing cyanobacteria. The Baltic Sea is an ideal environment to study the distribution of HGs and test their potential as biomarkers because of its recurring summer phytoplankton blooms, dominated by a few heterocystous cyanobacterial species of the genera Nodularia and Aphanizomenon. A multi-core and a gravity core from the Gotland Basin were analyzed to determine the abundance and distribution of a suite of selected HGs at a high resolution to investigate the changes in past cyanobacterial communities during the Holocene. The HG distribution of the sediments deposited during the Modern Warm Period (MoWP) was compared with those of cultivated heterocystous cyanobacteria, including those isolated from Baltic Sea waters, revealing high similarity. However, the abundance of HGs dropped substantially with depth, and this may be caused by either a decrease in the occurrence of the cyanobacterial blooms or diagenesis, resulting in partial destruction of the HGs. The record also shows that the HG distribution has remained stable since the Baltic turned into a brackish semi-enclosed basin 7200 cal. yr BP. This suggests that the heterocystous cyanobacterial species composition remained relatively stable as well. During the earlier freshwater phase of the Baltic (i.e., the Ancylus Lake and Yoldia Sea phases), the distribution of the HGs varied much more than in the subsequent brackish phase, and the absolute abundance of
\end{abstract}

HGs was much lower than during the brackish phase. This suggests that the cyanobacterial community adjusted to the different environmental conditions in the basin. Our results confirm the potential of HGs as a specific biomarker of heterocystous cyanobacteria in paleo-environmental studies.

\section{Introduction}

Cyanobacteria are a broad and diverse group of photoautotrophic bacteria; they are found in many terrestrial and aquatic environments (Whitton and Potts, 2012). They can exist as benthos or plankton and be unicellular or filamentous with or without branches, free-living or endosymbionts (Rippka et al., 1979) and are of biogeochemical significance due to their role in the cycling of carbon and nitrogen through photosynthesis and the fixation of $\mathrm{N}_{2}$. However, some $\mathrm{N}_{2}$ fixing cyanobacteria can negatively impact aquatic ecosystems due to their role in harmful algal blooms (HABs): exceptional events of phytoplankton growth causing anomalous feedbacks on food webs, alterations in the geochemical features of the water column (e.g., anoxia) and sometimes the release of harmful toxins into the environment. Cyanobacterial HABs (cHABs) affect the surface of lacustrine, estuarine and tropical marine environments worldwide; humaninduced global warming and nutrient overload are blamed 
for exacerbating the phenomenon (Paerl, 1988; Paerl et al., 2011; Paerl and Huisman, 2009).

The two processes of photosynthesis and $\mathrm{N}_{2}$ fixation are theoretically incompatible since the nitrogenase enzyme that catalyzes nitrogen fixation is inactivated by $\mathrm{O}_{2}$. To cope with this, $\mathrm{N}_{2}$-fixing cyanobacteria have developed several strategies (Stal, 2009). The filamentous diazotrophs of the orders Nostocales and Stigonematales spatially separate the two metabolisms by forming special cells dedicated to the fixation of $\mathrm{N}_{2}$, called heterocysts (Wolk, 1982; Adams, 2000). Gas exchange is believed to be regulated by the heterocyst cell wall, which consists of two separate polysaccharide and glycolipid layers (Murry and Wolk, 1989; Walsby, 1985), of which the latter acts as the gas diffusion barrier. These layers, known as heterocyst glycolipids (HGs), have been found to date to be unique to heterocyst-forming cyanobacteria (Bryce et al., 1972; Nichols and Wood, 1968), and furthermore their composition has been discovered to be distinct at the level of families and even genera (Bauersachs et al., 2009a, 2014a; Gambacorta et al., 1998; Schouten et al., 2013). Their structure comprises a sugar moiety glycosidically bound to a long $n$-alkyl chain (Fig. 1) with an even number of carbon atoms (26 to 32) with various functional groups (hydroxyl and keto groups) located at the C-3, $\omega-1$ and $\omega-3$ positions (Gambacorta et al., 1995, 1998; Schouten et al., 2013). The sugar moiety of HGs found in nonsymbiotic cyanobacteria is typically a hexose (hereafter $\mathrm{C}_{6}$ ) (Bryce et al., 1972; Lambein and Wolk, 1973; Nichols and Wood, 1968), while HGs associated with endosymbiotic heterocystous cyanobacteria have a pentose moiety (hereafter $\mathrm{C}_{5}$ ) (Bale et al., 2015, 2017; Schouten et al., 2013). High-performance liquid chromatography coupled to electrospray ionization tandem mass spectrometry (HPLC/ESI-MS ${ }^{2}$ ) has emerged as a rapid method to analyze HGs in cultures (Bauersachs et al.,, 2009a, c, 2014a) and modern-day ecosystems such as microbial mats, lakes and marine systems (Bale et al., 2015, 2016, 2017; Bauersachs et al., 2009c, 2011, 2013, 2015; Wörmer et al., 2012).

$\mathrm{C}_{6}$ HGs have been applied as specific paleo-biomarkers for the presence of $\mathrm{N}_{2}$-fixing cyanobacteria in marine geological records back to the Pleistocene and in lacustrine deposits back to the Eocene and hence have provided evidence of the high potential for HGs preservation in sedimentary records (Bauersachs et al., 2010). In addition, temperatureinduced modifications of the HG composition of heterocystous cyanobacteria were observed both in culture and in the environment and quantified by specific indices, suggesting the possible employment of HGs in reconstructing surface water temperatures (SWTs) (Bauersachs et al., 2009a, 2014b, 2015). However, in general, the application of HGs as a biomarker in environmental and paleo-environmental studies is still limited.

The Baltic Sea, characterized by the seasonal occurrence of cHABs mainly consisting of the HG-producing family Nostocaceae, presents an interesting location to both apply HGs as biomarkers in the present-day system and to investigate their potential as proxies for the reconstruction of past depositional environments. The modern Baltic, one of the world's largest brackish bodies of water, is a shallow, semi-enclosed basin, characterized by estuarine circulation, having its only connection to the North Sea through the Danish straits (Fig. 2). Irregular winter inflows of marine oxygen-rich water, known as salinity pulses, represent the main mechanism of renewing and mixing the bottom water, which otherwise experiences stagnation and increasing oxygen depletion with permanent stratification and persisting anoxia in its deep waters (Kononen et al., 1996). Since the last deglaciation (ca. 13-9 cal. kyr BP) the Baltic Sea has experienced specific hydrographical phases (Andrén et al., 2011). Following the ice retreat, the Baltic Ice Lake developed, which was followed by the Yoldia Sea phase, a short period when there was a connection with the sea. The subsequent Ancylus Lake phase (ca. 9.5-8.0 cal. kyr BP) was the last extended freshwater phase in the basin before a stable connection to the North Sea was established (Björck, 1995; Jensen et al., 1999). The transition phase began (ca. 7.87.3 cal. kyr BP) by a series of weak inflows of saline water, which eventually led to the fully brackish Littorina Sea phase ( 7.2-3.5 cal. kyr BP). The less brackish post-Littorina Sea phase (until $\sim 1.3 \mathrm{cal}$. kyr BP) followed, and the modern Baltic Sea is considered its natural continuation. In the last 1000 years, three consecutive periods occurred: the Medieval Warm Period (MWP), the Little Ice Age (LIA) and the current Modern Warm Period (MoWP, starting at 1950) (Kabel et al., 2012).

The modern Baltic undergoes summer cHABs primarily composed of a few species of filamentous heterocystous cyanobacteria: Nodularia spumigena, Aphanizomenon flosaquae and Anabaena spp. (Celepli et al., 2017; Hajdu et al., 2007; Hällfors, 2004; Kanoshina et al., 2003; Karjalainen et al., 2007; Ploug, 2008; Sivonen et al., 2007). Deep-water anoxia, high phosphorus availability, calm water conditions and high irradiation resulting in a relatively high sea surface temperature (SST) have been identified as the main triggers for these blooms. Anoxic sediments lead to the release of phosphate in the water column, stimulating new cHABs and further enhancing anoxia, resulting in a reinforcing feedback (Finni et al., 2001; Kabel et al., 2012; Paerl, 2008; Paerl et al., 2011; Poutanen and Nikkilä, 2001; Stipa, 2002). The summer cHABs have been documented since the 19th century, with a reported increase in their frequency and intensity in the last 60 years, which has been related to human-induced eutrophication (Bianchi et al., 2000; Finni et al., 2001).

Several studies, based on fossil pigment and other paleoproxy records, suggest that cHABs have been recurring throughout the entire Holocene simultaneously with anoxic events and thus should be considered a natural feature of the basin rather than a consequence of human impact (Bianchi et al., 2000; Borgendahl and Westman, 2007; Funkey et al., 2014; Poutanen and Nikkilä, 2001). SST has been suggested to have played an important role in these events (Kabel 
<smiles>CC(O)C(O)CCOC1OC(CO)C(O)C(O)C1O</smiles>

$\mathrm{C}_{26}$ diol<smiles>CC(=O)CCOC1OC(CO)C(O)C(O)C1O</smiles><smiles>CCC(=O)CCOC1OC(CO)C(O)C(O)C1O</smiles><smiles>CC(O)CC(O)CCOC1OC(CO)C(O)C(O)C1O</smiles><smiles>CC(O)CCOC1OC(CO)C(O)C(O)C1O</smiles><smiles>CC(O)C[14C](O)CCCOC1OC(CO)C(O)C(O)C1O</smiles>

Figure 1. Structures of the $\mathrm{C}_{6}$ heterocyst glycolipids (HG) targeted by the study. $\mathrm{C}_{26}$ diol HG (1-(O-hexose)-3,25-hexacosanediol); $\mathrm{C}_{26}$ ketool HG (1-(O-hexose)-3-keto-25-hexacosanol); $\mathrm{C}_{28}$ diol HG (1-(O-hexose)-3,27-octacosanediol); $\mathrm{C}_{28}$ keto-ol HG (1-(O-hexose)-3-keto-27octacosanol); $\mathrm{C}_{28}$ triol HG (1-(O-hexose)-3,25,27-octacosanetriol); $\mathrm{C}_{28}$ keto-diol HG (1-(O-hexose)-27-keto-3,25-octacosanediol).

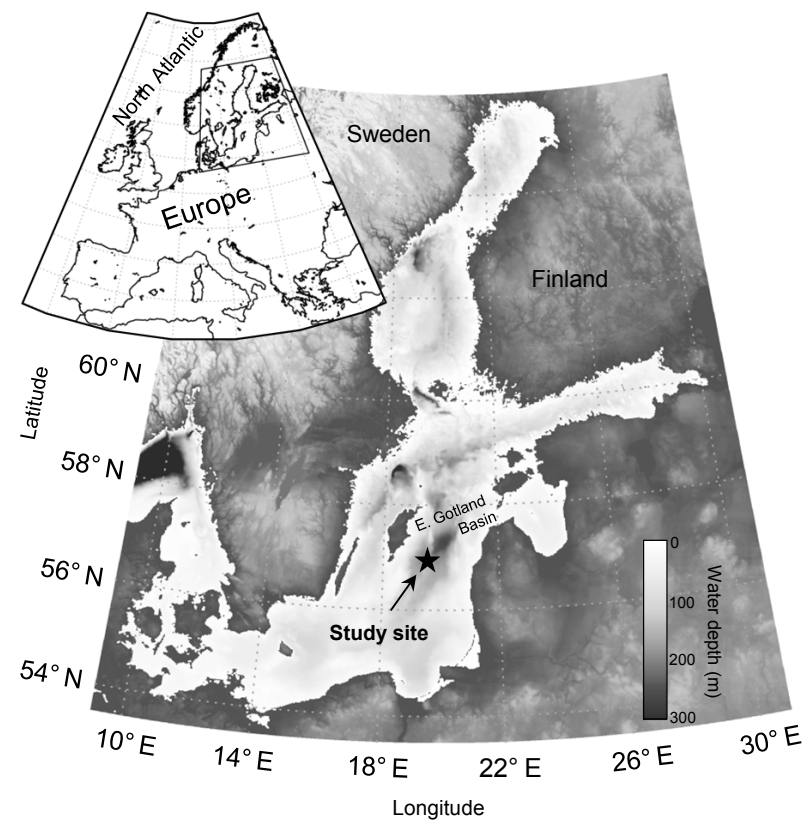

Figure 2. Map of the Baltic Sea. The location of multi-core (MUC) P435-1-4 and gravity core (GC) 303600 in the Eastern Gotland Basin is indicated with a black star (modified from Warden et al., 2017).

et al., 2012; Warden, 2017). Likely, at times of water column stratification and anoxia, high SST would have initiated cHABs in the basin when exceeding a threshold temperature of $\sim 16^{\circ} \mathrm{C}$, which is considered a trigger for the onset of the cHABs in the modern Baltic (Kononen, 1992; Wasmund, 1997). In addition, this would have enhanced the oxygen consumption of the deep water (Kabel et al., 2012).
The intrinsic occurrence of cHABs and their role in intensifying chronic anoxic events is not limited to the Baltic Sea. These same features have been observed in various stratified freshwater lakes in the Northern Hemisphere (Fritz, 1989; McGowan et al., 1999; Schweger and Hickman, 1989; Züllig, 1986). However, there is no full agreement regarding this interpretation, as other authors argue that human perturbation has to be considered to be the main driving force behind the co-occurrence of cHABs with anoxia in the Baltic (Zillén and Conley, 2010). Therefore, more research is required to elucidate the relationship between recurring anoxic events and cHABs in the Baltic Sea.

In this study, we test the potential of HGs as a paleo-proxy to investigate the changes in past communities involved in the summer cHABs in the Baltic Sea over the Holocene and the potential relationship with the anoxic events that occurred in the basin. To this end, a multi-core and a gravity core from the Gotland Basin were analyzed for HGs at a high resolution. The results of the analysis were compared with the total organic carbon content and the nitrogen isotope record. This may help in further confirming the potential of HGs as specific biomarkers of heterocystous cyanobacteria in environmental studies.

\section{Materials and methods}

\subsection{Sample site and sediment cores}

Our sampling site is located in the Eastern Gotland Basin, one of the deepest basins (max. $248 \mathrm{~m}$ ) within the Baltic Proper (Fig. 2). The gravity core (GC) 303600 (length $377 \mathrm{~cm}$ ) was collected in the Gotland Basin $\left(56^{\circ} 55.02^{\prime} \mathrm{N}\right.$, $19^{\circ} 19.98^{\prime} \mathrm{W}$ ) at $175 \mathrm{~m}$ water depth during a cruise onboard the R/V Prof. Albrecht Penck in July 2009. The multi-core (MUC) P435-1-4 (length $51.5 \mathrm{~cm}$ ) was also collected in the Gotland Basin $\left(56^{\circ} 57.94^{\prime} \mathrm{N}, 19^{\circ} 22.21^{\prime} \mathrm{E}\right)$ at $178 \mathrm{~m}$ wa- 
ter depth during cruise $\mathrm{P} 435$ onboard the R/V Poseidon in June 2012. The dating of the MUC and the brackish section of the GC was based on an age model, obtained by highresolution ${ }^{14} \mathrm{C}$ dating of benthic foraminifera (Warden, 2017; Warden et al., 2017), which allowed us to date the MUC (as calibrated kilo-years before present, cal. kyrBP, and the corresponding $\mathrm{AD}$ date) and the GC (as cal. kyr BP) back to $230 \mathrm{~cm}$ depth, which corresponds to ca. $7200 \mathrm{cal}$. yr BP.

The GC was cut into two halves and subsampled at a high resolution with $1 \mathrm{~cm}$ slices from 0 to $237 \mathrm{~cm}$ and $2 \mathrm{~cm}$ slices from 237 to $377 \mathrm{~cm}$. During the procedure, the depths $81-$ $82 \mathrm{~cm}$ and $187-188 \mathrm{~cm}$ were missed. The MUC was subsampled at $0.5 \mathrm{~cm}$ resolution. The sediments obtained were freeze-dried and ground before further analysis.

\subsection{Elemental and stable isotope analysis}

Subsamples were taken from the GC sediment slices for determination of the total organic carbon (TOC) content at the Leibniz Institute for Baltic Sea Research (IOW) and for the analysis of bulk stable nitrogen isotopes $\left({ }^{15} \mathrm{~N}\right)$ at the Royal Netherlands Institute for Sea Research (NIOZ). The total carbon (TC) content of the sediments of the MUC and GC was measured by using an EA $1110 \mathrm{CHN}$ analyzer from CE Instruments, while a Multi EA-2000 Elemental Analyzer (Analytic, Jena, DE) was employed to determine the total inorganic carbon (TIC). The TOC content was calculated as the difference between TC and TIC and expressed in weight percentage (wt \%). The $\delta^{15} \mathrm{~N}$ was analyzed in duplicate on a Thermo Finnigan Delta Plus isotope ratio mass spectrometer (irmMS) connected to a Flash 2000 elemental analyzer (Thermo Fisher Scientific, Milan, Italy). The precision of the isotope analysis was $0.2 \%$ for nitrogen measurements.

\subsection{Lipid extraction and analysis}

All slices from the MUC and alternating slices from the GC were extracted and analyzed for their HG content and distribution. The extraction was performed using an accelerated solvent extractor (ASE 200, DIONEX; $100^{\circ} \mathrm{C}$ and $7.6 \times 10^{6}$ $\mathrm{Pa}$ ) with a mixture of dichloromethane (DCM): methanol $(\mathrm{MeOH})(9: 1, v / v)$, to obtain a total lipid extract (TLE), which was dried under a flow of $\mathrm{N}_{2}$. TLE was redissolved by sonication (10 min) in DCM/MeOH $(1: 1, v / v)$, and aliquots were taken and dried under a flow of $\mathrm{N}_{2}$. These aliquots were dissolved in hexane, isopropanol and water $(72: 27: 1$, $v / v / v)$ and filtered through a $0.45 \mu \mathrm{m}$ regenerated cellulose syringe filter (4 mm diameter; Grace Alltech). Samples were analyzed by using a HPLC-triple quadrupole mass spectrometry (MS) in multi-reaction monitoring (MRM) mode as described by Bale et al. (2015). For the analysis, an Agilent (Palo-Alto, CA, US) 1100 series HPLC with a thermostatcontrolled auto-injector was employed coupled to a Thermo TSQ Quantum EM triple quadrupole MS equipped with an Ion Max source with an electrospray ionization (ESI) probe. The MRM method specifically targets $\mathrm{C}_{5}$ and $\mathrm{C}_{6}$ HGs with alkyl chains containing 26 and 28 carbon atoms (Bale et al., 2015). HGs were quantified as the integrated peak area per gram of TOC (response units, r.u. gTOC $^{-1}$ ). The r.u. $\mathrm{gTOC}^{-1}$ values were simplified for practical purpose by dividing them by $1 \times 10^{10}$. For the MUC, $30 \%$ of the samples were reanalyzed as duplicates; the calculated relative SD was on average $5.3 \%$. For all GC samples we performed the HPLC $/ \mathrm{MS}^{2}$ analysis twice; in this case the calculated relative SD was on average $12.4 \%$.

A selected number of samples was analyzed in fullscan mode using an ultra high-pressure liquid chromatography high-resolution mass spectrometry (UHPLC-HRMS) method (Moore et al., 2013) as follows: we used an Ultimate 3000 RS UHPLC, equipped with thermostatted auto-injector and column oven, coupled to a Q Exactive Orbitrap MS with Ion Max source with heated electrospray ionization (HESI) probe (Thermo Fisher Scientific, Waltham, MA). Separation was achieved on an Acquity UPLC BEH HILIC column $(150 \times 2.0 \mathrm{~mm}, 2.1 \mu \mathrm{m}$ particles, pore size $12 \mathrm{~nm}$; Waters, Milford, MA) maintained at $30^{\circ} \mathrm{C}$. Elution was achieved with hexane-propanol-formic acid $14.8 \mathrm{molL}^{-1}$ aqueous $\mathrm{NH}_{3}(79: 20: 0.12: 0.04, v / v / v / v)$, hereafter $\mathrm{A}$, and propanol water-formic acid $14.8 \mathrm{molL}^{-1}$ aqueous $\mathrm{NH}_{3}(88: 10: 0.12: 0.04, v / v / v / v)$, hereafter $\mathrm{B}$, starting at $100 \% \mathrm{~A}$, followed by a linear increase to $30 \% \mathrm{~B}$ at $20 \mathrm{~min}$, followed by a $15 \mathrm{~min}$ hold and a further increase to $60 \% \mathrm{~B}$ at $50 \mathrm{~min}$. The flow rate was $0.2 \mathrm{~mL} \mathrm{~min}^{-1}$; the total run time was $70 \mathrm{~min}$, followed by a $20 \mathrm{~min}$ re-equilibration period. Positive ion ESI settings were as follows: capillary temperature $-275^{\circ} \mathrm{C}$; sheath gas $\left(\mathrm{N}_{2}\right)$ pressure -35 arbitrary units (AU); auxiliary gas $\left(\mathrm{N}_{2}\right)$ pressure $-10 \mathrm{AU}$; spray voltage $-4.0 \mathrm{kV}$; probe heater temperature $-275^{\circ} \mathrm{C}$; S-lens $-50 \mathrm{~V}$. Target lipids were analyzed with a mass range of $m / z$ 350-2000 (resolution $70000 \mathrm{ppm}$ at $m / z$ 200), followed by data-dependent tandem $\mathrm{MS}^{2}$ (resolution $17500 \mathrm{ppm}$ ), in which the 10 most abundant masses in the mass spectrum were fragmented successively (normalized collision energy: 35 ; isolation width: $1.0 \mathrm{~m} / \mathrm{z}$ ). The Q Exactive was calibrated within a mass accuracy range of $1 \mathrm{ppm}$ using the Thermo Scientific Pierce LTQ Velos ESI Positive Ion Calibration Solution. During analysis dynamic exclusion was used to temporarily exclude masses (for $6 \mathrm{~s}$ ) in order to allow the selection of less abundant ions for $\mathrm{MS}^{2}$.

A number of indices have been suggested to express the correlation between the distribution of HGs and growth temperature (Bauersachs et al., 2009a, 2014b, 2015). We examined our data using two such indices, the $\mathrm{HDI}_{26}$ and the $\mathrm{HDI}_{28}$ (heterocyst diol index of 26 and 28 carbon atoms, respectively), defined as follows:

$$
\begin{aligned}
& \mathrm{HDI}_{26}=\frac{\mathrm{HG}_{26} \text { diol }}{\mathrm{HG}_{26} \text { keto-ol }+\mathrm{HG}_{26} \text { diol }}, \\
& \mathrm{HDI}_{26}=0.0224 \times \mathrm{SWT}+0.4381 ; \quad r^{2}=0.93,
\end{aligned}
$$


(a)

(b)

(c)

(d)

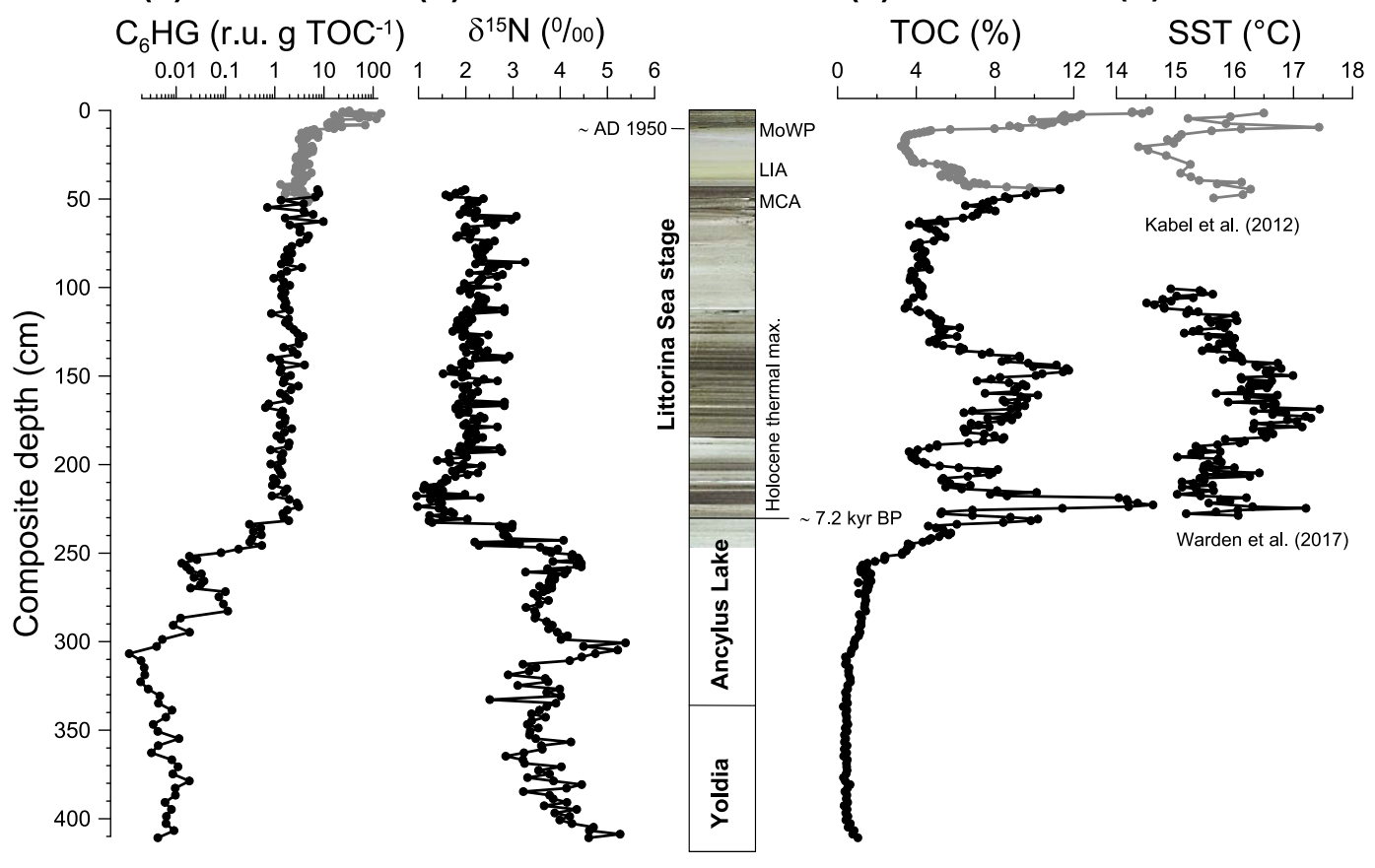

Figure 3. Proxy records of the Baltic Sea cores on a composite depth scale aligned with core photos showing the lamination of the sediments of the post-Ancylus Lake stage. (a) The abundance of the HGs (r.u.gTOC ${ }^{-1}$ ) on a log scale; (b) $\delta^{15} \mathrm{~N}(\%$ ); (c) TOC content (\%) partly derived from Warden et al. (2017); and (d) TEX 86 -derived summer sea surface temperatures (SSTs) from Kabel et al. (2012) and Warden et al. (2017). Data points derived from the MUC P435-1-4 core are in gray, and those from the GC 303600 core are in black. The stratigraphy is based on age models published elsewhere (Kabel et al., 2012; Warden et al., 2017), and for the deeper part of the GC 303600 core, it is based on unpublished data on diatom assemblages. The TEX ${ }_{86}$ data of Kabel et al. (2012) were measured on a different core (MUC 303 600) obtained from the same site, which was correlated to the MUC P435-1-4 core based on the TOC profiles (Fig. S1 in the Supplement). Note that phases characterized by the deposition of laminated sediments are the periods during the Holocene when the bottom waters of the Baltic Sea were anoxic.

$\begin{aligned} \mathrm{HDI}_{28} & =\frac{\mathrm{HG}_{28} \text { diol }}{\mathrm{HG}_{28} \text { keto-ol }+\mathrm{HG}_{28} \text { diol }}, \\ \mathrm{HDI}_{28} & =0.0405 \times \mathrm{SWT}+0.0401 ; \quad r^{2}=0.70 .\end{aligned}$

These SWT calibrations have been determined in a study of a freshwater lake (Lake Schreventeich, Kiel, Germany; Bauersachs et al., 2015).

\subsection{Data analysis}

Principal component analysis (PCA) was performed with the $\mathrm{R}$ software package for statistical computing, to test the variation observed in the HG distribution.

\section{Results}

\subsection{Sediment core characteristics}

The basin has experienced periodical anoxic bottom waters, which resulted in the alternating deposition of laminated and homogeneous sediments (Fig. 3; see also Andrén et al., 2000). The sediments of the MUC represent al- most 1000 years of sedimentation and comprise the MoWP ( $\sim 0-11 \mathrm{~cm}$ depth, corresponding to $\sim 2012-1950$ AD or -0.06 to 0 cal kyr BP), the LIA $(\sim 12-41 \mathrm{~cm}$, corresponding to $\sim 1950-1260 \mathrm{AD}$ or $\sim 0.1-0.7 \mathrm{cal} \mathrm{kyr} \mathrm{BP})$ and almost the entire MWP $(\sim 42-52 \mathrm{~cm}$, corresponding to $\sim 0.7$ 0.9 cal kyr BP). The upper part of the GC overlaps with the deeper part of the MUC (i.e., $\sim 0$ to $17 \mathrm{~cm}$ depth in the GC roughly corresponds to $\sim 35$ to $52 \mathrm{~cm}$ of the MUC). The upper part of the GC covers the initial phases of the LIA (until ca. $6 \mathrm{~cm}, \sim 0.6 \mathrm{cal} \mathrm{kyr} \mathrm{BP}$ ) and the complete Littorina Sea and Ancylus Lake stages, down to part of the Yoldia Sea stage.

\subsection{Abundance and distribution of HGs}

In total 104 sediment horizons of the MUC and 153 horizons of the $\mathrm{GC}$ were analyzed for $\mathrm{C}_{6}$ and $\mathrm{C}_{5} \mathrm{HGs}$ with alkyl chains with 26 and 28 carbon atoms using HPLC-triple quadrupole MS in MRM mode as described by Bale et al. (2015). Bauersachs et al. (2017) have recently analyzed the HGs of eight representative heterocystous cyanobacterial strains isolated from the Baltic Sea, and the six $\mathrm{C}_{6}$ HGs targeted in our study 
(a)

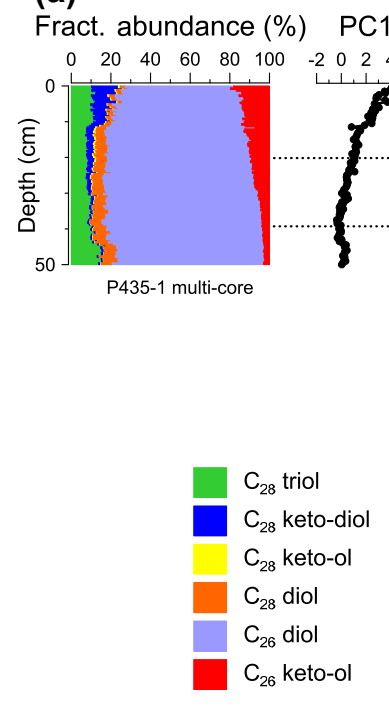

(b)

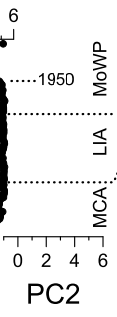

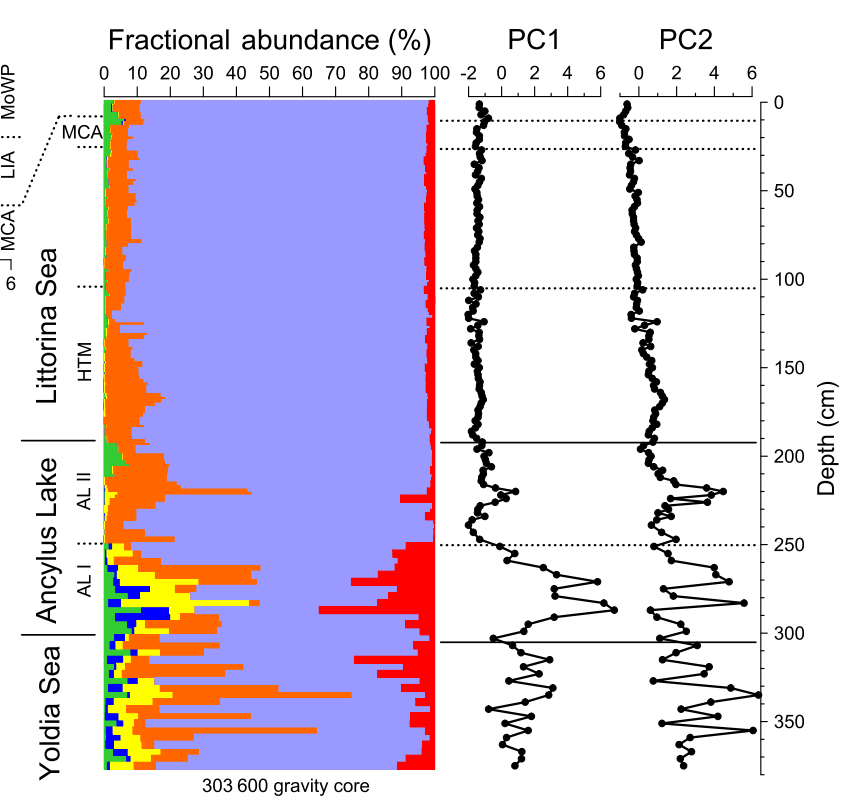

Figure 4. Distribution of HGs, displayed as fractional abundance (\%) vs. depth (in $\mathrm{cm}$ ) for (a) the MUC P435-1-4 core and (b) the GC 303600 core. Color key: light green $-\mathrm{C}_{28}$ triol HG; blue $-\mathrm{C}_{28}$ keto-diol HG; yellow $-\mathrm{C}_{28}$ diol HG; orange $-\mathrm{C}_{28} \mathrm{keto}-\mathrm{ol} \mathrm{HG}$; purple $-\mathrm{C}_{26}$ diol HG; red $-\mathrm{C}_{26}$ keto-ol HG. Each sample represents a sediment slice of $0.5 \mathrm{~cm}$ in the case of the MUC and of 1 or $2 \mathrm{~cm}$ in the case of the GC. The stratigraphy of the cores (see Fig. 3) is indicated. The scores on PC1 and PC2 derived from the principal component analysis of the HG distribution are plotted along the fractional abundance plots using the same scale for both cores.

form by far the majority (i.e., 97.7-100\%) of the HGs of these strains. HGs with longer alkyl chains were not detected, suggesting that, at least for the brackish phase, our analysis method will provide a proper view of changes in the overall HG distribution.

$\mathrm{C}_{5}$ HGs were not detected at all, but the targeted $\mathrm{C}_{6}$ HGs were present in all samples of both cores. The $\mathrm{C}_{6}$ HGs detected in this study were as follows: 1-(Ohexose)-3,25-hexacosanediol $\left(\mathrm{C}_{26}\right.$ diol HG; see Fig. 1 for structures); 1-(O-hexose)-3-keto-25-hexacosanol ( $\mathrm{C}_{26}$ ketool HG); 1-(O-hexose)-3,27-octacosanediol ( $\mathrm{C}_{28}$ diol $\left.\mathrm{HG}\right)$; 1-(O-hexose)-3-keto-27-octacosanol $\left(\mathrm{C}_{28}\right.$ keto-ol HG); 1(O-hexose)-3,25,27-octacosanetriol $\left(\mathrm{C}_{28}\right.$ triol $\left.\mathrm{HG}\right)$; 1-(Ohexose)-27-keto-3,25-octacosanediol ( $\mathrm{C}_{28}$ keto-diol $\left.\mathrm{HG}\right)$. A selected number of samples from the brackish phase was also analyzed in full-scan mode to check for the presence of HGs with longer alkyl side chains, but these were not encountered (Table 2). The HG distribution obtained using this method was comparable to that obtained with the HPLCtriple quadrupole MS method.

The distribution of the six quantified HGs changed substantially with depth (Fig. 4). The $\mathrm{C}_{26}$ diol HG was the dominant component, accounting for $\sim 50$ to $95 \%$ of the HGs, in the sediments recording the brackish phase of the basin. In the sediments deposited during the Ancylus Lake and Yoldia phase (i.e., below $213 \mathrm{~cm}$ of the GC), the fractional abundance of the $\mathrm{C}_{26}$ diol $\mathrm{HG}$ was more variable, reaching only
20-30\% at some discrete depths. In the sediments deposited during the brackish phase, the fractional abundance of all keto HGs (i.e., $\mathrm{C}_{26}$ keto-ol HG, $\mathrm{C}_{28}$ keto-ol HG and $\mathrm{C}_{28}$ ketodiol HG) diminished with increasing depth, roughly from 3$15 \%$ to $<2 \%$ (Fig. 4 b). In the sediments deposited during the Ancylus Lake and Yoldia Sea phase, however, their fractional abundance showed more variation, and in general it increased and reached $\sim 10-40 \%$ at some specific depths. The fractional abundance of the $\mathrm{C}_{28}$ diol $\mathrm{HG}$ remained steady for most of the sediments deposited during the brackish phase ( $\sim 10 \%$ on average), although slightly increased values occurred in the oldest part of the brackish section, up to $\sim 15 \%$ (Fig. 4b). In the Ancylus Lake and Yoldia Sea section the fractional abundance of the $\mathrm{C}_{28}$ diol HG was higher, with values sometimes reaching almost $60 \%$, but it was also more variable. The fractional abundance of the $\mathrm{C}_{28}$ triol $\mathrm{HG}$ was $<2 \%$ for most of the sediments deposited during the brackish phase, with the exceptions of the shallower (8-16\%) and the deeper part, close to the boundary with the freshwater phase (3-9\%). In the Ancylus Lake and Yoldia Sea sections, the relative abundance of the $\mathrm{C}_{28}$ triol $\mathrm{HG}$ generally remained $<2 \%$, although it was between $3-11 \%$ in several horizons in the deeper part (Fig. 4b). For the Ancylus Lake and Yoldia Sea section, we did not check the general distribution of the HGs and, therefore, cannot exclude the possibility that HGs with alkyl chains $>28$ carbon atoms occur during these intervals. 

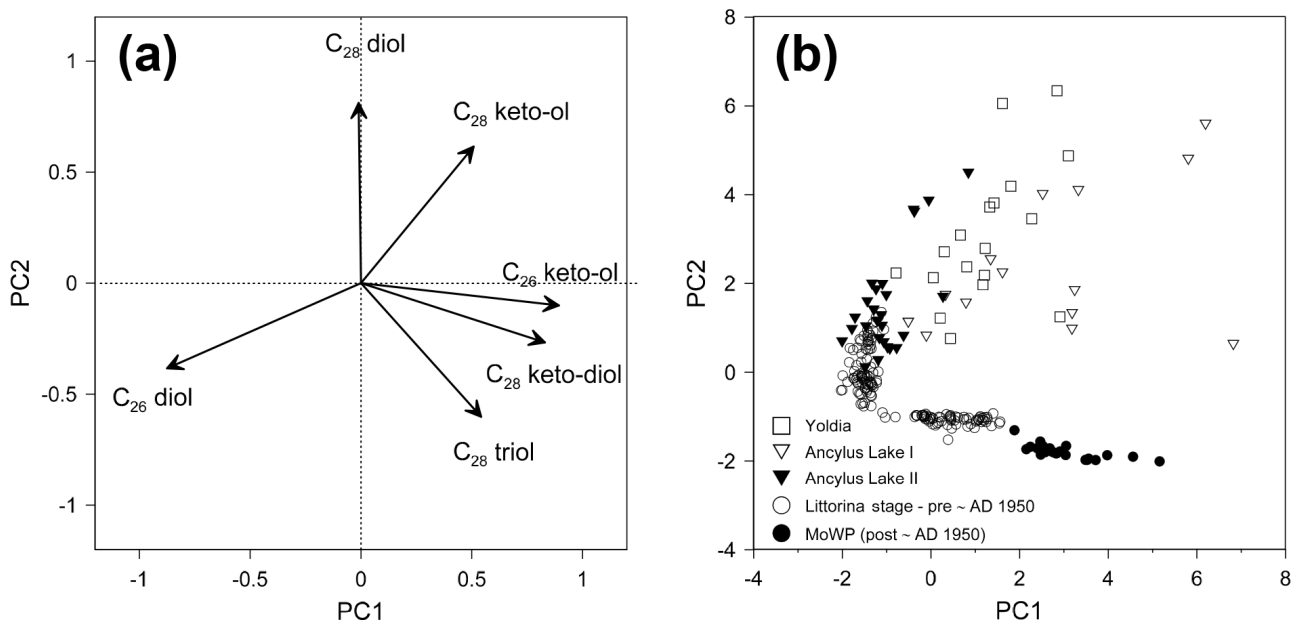

Figure 5. Principal component analysis of the heterocyst glycolipid (HG) distribution in the sediments recovered by the MUC P435-1-4 and the GC 303600 cores from the Gotland Basin, Baltic Sea. (a) The loadings of the six HGs on the first two principal components (PCs), with PC1 accounting for the $47 \%$ and PC2 for $29 \%$ of the variance. (b) Scores of the sediments from various stages on PC1 and PC2.

The $\mathrm{C}_{6} \mathrm{HG}$ abundance (sum of the six $\mathrm{C}_{6} \mathrm{HGs}$; hereafter referred to as $\mathrm{HG}$ abundance) profile showed four peaks in the first $8 \mathrm{~cm}$ of the MUC of 144, 82, 117 and 69 r.u. gTOC $^{-1}$ (Fig. 3a). After this last peak, the abundance of the HGs decreased substantially by a factor of $\sim 30$ in some cases (i.e., $\sim 5$ r.u. gTOC $^{-1}$ ) and remained at this level with increasing depth over the whole of the MUC (Fig. 3a).

The HG abundance in the upper part of the GC (up to $\sim 11 \mathrm{~cm}$ ) was 3 to 6 times higher (7 to 18 r.u. TOOC $^{-1}$ ) than that recorded in the corresponding fraction of the MUC ( 2 to 4 r.u. $\mathrm{gTOC}^{-1}$ ). At $\sim 17 \mathrm{~cm}$ of the GC, which is equivalent to $\sim 52 \mathrm{~cm}$ or the bottom of the MUC, the abundances were in the same order of magnitude ( 4 to 5 r.u.gTOC ${ }^{-1}$ ). Between $\sim 25$ and $213 \mathrm{~cm}$ depth $(\sim 1.3-7.1 \mathrm{cal} \mathrm{kyrBP})$, the abundance of the HGs decreased substantially further by a factor of ca. 6 to 10, with the exception of several small peaks at discrete depths $\left(\sim 5\right.$ r.u. gTOC $^{-1}$ at $\sim 35 \mathrm{~cm} ; \sim 4$ r.u. gTOC $^{-1}$ at $\sim 53 \mathrm{~cm}$, at $\sim 92 \mathrm{~cm}$ and at $\sim 108 \mathrm{~cm} ; \sim 3$ r.u. gTOC $^{-1}$ at $\sim 188 \mathrm{~cm})$. Deeper in the core $(213-375 \mathrm{~cm}$; i.e., the Ancylus Lake and Yoldia phase), the abundance of the HGs was even lower (Fig. 3a).

\subsection{Principal component analysis of the HG distribution}

The variation observed in the HG distribution in the sediments was examined by applying a principal component analysis (PCA) to the fractional abundances of the six HGs (Fig. 5). The first two PCs explained most of the variation observed, accounting for 47 and $29 \%$ of the variance (Fig. 5a). The first principal component (PC1) showed a positive loading of all keto HGs and of the $\mathrm{C}_{28}$ triol HG. Specifically, the $\mathrm{C}_{26}$ keto-ol HG and the $\mathrm{C}_{28}$ keto-diol HG had the most positive loading (Fig. 5a). The $\mathrm{C}_{26}$ diol HG was the only component showing a negative loading in $\mathrm{PC} 1$; the $\mathrm{C}_{28}$ diol $\mathrm{HG}$ did not show any loading on PC1. PC2 was primarily determined by the positive loadings of the $\mathrm{C}_{28}$ diol and keto-ol HGs, whereas all other HGs had negative loadings on PC2.

Figure 5b shows the scores of all analyzed sediment horizons on PC1 and PC2, which reveals clearly defined different signatures. The brackish phase sediments all scored negatively or just above zero on PC2. However, the score on PC1 was more variable; the MoWP sediments scored most positively on PC1, whereas the pre-MoWP brackish sediment scored less positively on $\mathrm{PC} 1$, which is due to the higher fractional abundances of the $\mathrm{C}_{26}$ keto-ol and $\mathrm{C}_{28}$ keto-diol HGs in the MoWP sediments. The remaining sediments of the Ancylus Lake I and Yoldia Sea phase all scored positively on both PC1 and PC2, and therefore distinctly from the brackish phase sediments, but they also showed much more variability. The sediments of the Ancylus Lake transitional phase II (filled triangles in Fig. 5b) plotted much more closely to those of the brackish phase, with some data points with similar PC1 and PC2 values.

Figure 4 shows the variation in the scores on $\mathrm{PC} 1$ and $\mathrm{PC} 2$ with depth. The sediments of the MUC exhibited a decreasing trend in PC1 with increasing depth, caused by the reduction in the fractional abundance of the positively scoring keto $\mathrm{HGs}$, in favor of the negatively scoring $\mathrm{C}_{26}$ diol (Fig. 4a). For the GC (Fig. 4b), the PC1 scores varied between -2 and -1 , from the top up to $213 \mathrm{~cm}$ depth (i.e., the brackish phase), consistent with the dominance of the $\mathrm{C}_{26}$ diol HG in this section. At greater depth (i.e., the Ancylus Lake and Yoldia Sea phases), large variations in the score of PC1 were observed (Fig. 4b). Scores were mostly positive; negative PC1 scores were only found at three discrete depths, i.e., 239, 303 and $343 \mathrm{~cm}$. The generally positive score in these phases highlights the greater contribution of HGs other than $\mathrm{C}_{26}$ diol HG. The PC2 score of the sediments of the MUC was con- 
stantly around -1 (Fig. 4a). In the GC, PC2 was close to zero during the brackish water phase (Fig. $4 \mathrm{~b}$ ). In the sediments of the Ancylus Lake and Yoldia Sea phases the PC2 score was generally positive, clearly influenced by the higher fractional abundance of positively scoring $\mathrm{C}_{28}$ diol and $\mathrm{C}_{28}$ keto-ol HGs, but variable.

\section{Discussion}

This study investigates the presence of HGs in the recent sedimentary record of the Baltic Sea and represents the first attempt to relate them with the recurring anoxic events that took place in the basin during the Holocene as well as the ongoing increase in cHAB over the last 60 years. In our data set we recognized various phases, characterized by different distributions of HGs (cf. Figs. 4 and 5b). Here these records and their implications for the heterocystous cyanobacterial community composition are discussed.

\subsection{The distribution of HGs}

The composition of HGs in cyanobacteria is known to be related to their taxonomy (Bauersachs et al., 2009a, 2014a; Gambacorta et al., 1995, 1998; Schouten et al., 2013; Wörmer et al., 2012). Hence, we compared the distribution of the HGs observed in our sedimentary record of the Baltic Sea with the HGs produced in vitro by different heterocystous cyanobacterial species.

\subsubsection{Brackish sediments}

Firstly, the most recent sediments (MoWP; $<11 \mathrm{~cm}$ depth of MUC) were compared with species that thrive in the modern Baltic Sea (Table 1). The recurring late summer (JulyAugust) cHABs of the Baltic are dominated by the taxa Nodularia spumigena, Aphanizomenon flos-aquae and, to a minor extent, by Anabaena spp. and other species from the order Nostocales, family Nostocaceae (Hajdu et al., 2007; Hällfors, 2004; Kanoshina et al., 2003; Karjalainen et al., 2007; Sivonen et al., 2007; Celepli et al., 2017). While the Nodularia genus is usually prevalent, changes in the composition of the community have been observed from the early to the late stage of the $\mathrm{cHAB}$ and from one year to another, resulting in a large variation in its features over time (Finni et al., 2001; Hajdu et al., 2007; Kahru et al., 1994; Wasmund, 1997). A recent extensive meta-omics study revealed that in the Baltic Proper (the predominant area for cHABs), $69 \%$ of the heterocystous cyanobacteria belong to Aphanizomenon, $23 \%$ to Anabaena and $8 \%$ to Nodularia (Celepli et al., 2017).

The HG distribution in the MoWP sediments, with the $\mathrm{C}_{26}$ diol as the dominant HG (Fig. 4a, summarized in Table 1), agrees well with the HG distribution in cultures of Nodularia, Aphanizomenon and Anabaena as well as other members of the Nostocaceae family (Table 1), including those that have been isolated from the Baltic (Bauersachs et al., 2009a, 2017). These cultures generally also synthesized minor amounts of the $\mathrm{C}_{26}$ keto-ol $\mathrm{HG}$, as was seen in the MoWP sediments. The $\mathrm{C}_{28}$ diol, present in trace amounts in the MoWP sediments, was found in varying amounts in the Nodularia, Aphanizomenon and Anabaena cultures. Even between different strains of the same species, the amounts present were highly variable, from a dominant component to not detected (Table 1). The $\mathrm{C}_{28}$ keto-ol, $\mathrm{C}_{28}$ triol and $\mathrm{C}_{28}$ keto-diol HGs were minor components in the MoWP sediments. While not produced consistently across the Nodularia, Aphanizomenon and Anabaena cultures, they were found in certain strains, generally as trace or minor components, in agreement with the distribution in the sediments (Table 1). It is possible, however, that the presence of the $\mathrm{C}_{28}$ triol HG in the MoWP sediments may be linked to the presence of the genus Calothrix (cf. Table 1), which is commonly found in the rocky seabed of the basin (Sivonen et al., 2007).

Overall, the distribution of the HGs observed in the MoWP sediments was in good agreement with the HG distribution of the family Nostocaceae (Table 1), which fits in with the reported dominance of members of this family during the summer cHABs of the Baltic. Furthermore, the HG distribution remained relatively constant throughout the MoWP sediments (Fig. 4a), suggesting that overall the community composition of heterocystous cyanobacteria in the Baltic Sea has remained stable during the last $\sim 60$ years.

The HG distribution in the sediment from the pre-MoWP brackish phase (i.e., from the Ancylus Lake-Littorina Sea (AL-LS) transition to the start of the MoWP) reconstructed in this study was similar to that of the MoWP, although the $\mathrm{C}_{26}$ diol and the $\mathrm{C}_{28}$ diol were present in a greater fractional abundance (Table 1; Fig. 4). The other four HGs were either minor or occurred in traces. Although often absent, a number of Nostocaceae strains have been found to contain the $\mathrm{C}_{28}$ diol (Table 1), and in one Anabaena sp. strain (CCY9402), it was found to be the dominant HG (Bauersachs et al., 2009a). The increased proportion of the $\mathrm{C}_{28}$ diol through the preMoWP brackish phase suggests there was a somewhat different cyanobacterial community composition than during the MoWP, although most probably still dominated by cyanobacteria belonging to the family Nostocaceae. The HG distribution remained relatively constant from the establishment of the brackish phase to the MoWP (Fig. 4), which suggests that the cyanobacterial community of the Baltic did not undergo major changes from the AL-LS transition to the MoWP and remained dominated by cyanobacteria belonging to the family Nostocaceae.

\subsubsection{The Ancylus Lake sediments}

The Ancylus Lake phase displayed a distinct HG distribution from the brackish phase (Fig. 4b; summarized in Table 1). The $\mathrm{C}_{28}$ diol was often dominant and both the $\mathrm{C}_{26}$ and $\mathrm{C}_{28}$ keto-ol were present in a higher proportion than during the 
Table 1. Distribution of the six targeted HGs in sediments from this study and from cultures of selected heterocystous cyanobacteria. Key: ++- dominant $(>25 \%) ;+-$ minor presence $(5-25 \%)$; tr. - traces $(<5 \%) ;--$ not detected or not reported. Bold strains were isolated from the Baltic Sea.

\begin{tabular}{|c|c|c|c|c|c|c|c|}
\hline Baltic sediment & & $\mathrm{C}_{26}$ diol & $\mathrm{C}_{26}$ keto-ol & $\mathrm{C}_{28}$ diol & $\mathrm{C}_{28}$ keto-ol & $\mathrm{C}_{28}$ triol & $\mathrm{C}_{28}$ keto-dio \\
\hline MoWP & & ++ & + & tr. & tr. & + & + \\
\hline Pre-MoWP brackish & & ++ & $+/$ tr. & + & $\operatorname{tr}$ & $+/$ tr. & tr. \\
\hline Ancylus Lake-II & & ++ & $+/ \operatorname{tr}$ & $++/+$ & tr. $/-$ & tr. $/-$ & \\
\hline Ancylus Lake-I & & ++ & $++/+$ & $++/-$ & $++/ \operatorname{tr}$ & $+/ \operatorname{tr}$ & $+/$ tr. \\
\hline Yoldia Sea & & ++ & + & $++/+$ & $+/ \operatorname{tr}$ & $+/ \operatorname{tr}$ & tr. \\
\hline Nostocaceae cultures & Strain ID & & & & & & \\
\hline Nodularia sp. ${ }^{\mathrm{a}}$ & CCY $9414 \& 9416$ & ++ & + & - & - & - & - \\
\hline Nodularia sp. ${ }^{\mathrm{b}}$ & BY1 & ++ & + & - & - & - & - \\
\hline Nodularia sp. ${ }^{\mathrm{b}}$ & F81 & ++ & + & - & - & - & - \\
\hline Nodularia sp. ${ }^{\mathrm{b}}$ & AV1 & ++ & + & - & - & - & - \\
\hline Nodularia sp. ${ }^{\mathrm{b}}$ & HEM & ++ & + & - & - & - & - \\
\hline Nodularia chucula ${ }^{\mathrm{a}}$ & CCY 0103 & ++ & + & - & - & - & - \\
\hline Aphanizomenon sp. ${ }^{\mathrm{a}}$ & CCY 0368 & ++ & + & + & - & - & - \\
\hline Aphanizomenon sp. ${ }^{\mathrm{a}}$ & CCY 9905 & ++ & + & + & + & tr. & tr. \\
\hline Aphanizomenon sp. ${ }^{\mathrm{b}}$ & TR183 & ++ & + & tr. & - & + & tr. \\
\hline A. aphanizomenoides ${ }^{\mathrm{c}}$ & UAM 523 & + & - & ++ & + & tr. & - \\
\hline A. gracile $^{\mathrm{c}}$ & UAM 521 & ++ & ++ & tr. & - & tr. & - \\
\hline A. ovalisporum $\mathrm{c}, \mathrm{f}$ & UAM 290 & ++ & tr. & tr. & $\operatorname{tr}$. & - & - \\
\hline Anabaena sp. ${ }^{\mathrm{a}}$ & CCY 0017, 9910, & ++ & + & + & + & - & - \\
\hline Anabaena sp. $^{\mathrm{a}}$ & CCY 9402 & - & - & ++ & + & - & - \\
\hline Anabaena sp. $^{\mathrm{a}}$ & CCY 9613 & + & + & - & - & - & - \\
\hline Anabaena sp. ${ }^{\mathrm{a}}$ & CCY 9614, 9922 & ++ & + & - & - & - & - \\
\hline Anabaena sp. ${ }^{\mathrm{b}}$ & 315 & ++ & ++ & tr. & tr. & tr. & - \\
\hline Anabaena sp. ${ }^{\mathrm{b}}$ & BIR53 & ++ & ++ & tr. & tr. & tr. & - \\
\hline Anabaena sp. ${ }^{\mathrm{b}}$ & BIR169 & ++ & + & tr. & tr. & ++ & + \\
\hline Anabaena cylindrica ${ }^{\mathrm{a}}$ & CCY 9921 & ++ & + & - & - & - & - \\
\hline Anabaenopsis sp. ${ }^{\mathrm{a}}$ & CCY 0520 & ++ & + & + & - & - & - \\
\hline Nostoc sp. $^{\mathrm{a}}$ & CCY 0012, 9926 & ++ & + & - & - & - & - \\
\hline Nostoc sp. ${ }^{\mathrm{c}}$ & MA 4 & ++ & ++ & $\operatorname{tr}$. & - & tr. & - \\
\hline Cylindrospermopsis raciborskic ${ }^{\mathrm{c}}, \mathrm{f}$ & UAM 520 & ++ & tr. & + & $\operatorname{tr}$. & + & - \\
\hline Cyanospira rippkae & ATCC 43194 & - & - & ++ & + & - & - \\
\hline \multicolumn{8}{|l|}{ Rivulariaceae cultures } \\
\hline Calothrix desertica $^{\mathrm{d}}$ & PCC 7102 & - & - & - & - & ++ & ++ \\
\hline Calothrix sp. ${ }^{\mathrm{c}}$ & MU 27 & - & - & $\operatorname{tr}$. & - & ++ & ++ \\
\hline Calothrix sp. ${ }^{\mathrm{a}}$ & CCY 0018 & - & - & - & - & ++ & + \\
\hline Calothrix sp. ${ }^{\mathrm{a}}$ & CCY 0202 & tr. & tr. & - & - & ++ & + \\
\hline Calothrix sp. ${ }^{\mathrm{a}}$ & CCY 0327 & - & - & - & - & ++ & + \\
\hline Calothrix sp. ${ }^{\mathrm{a}}$ & CCY 9923 & - & - & + & + & ++ & + \\
\hline \multicolumn{8}{|l|}{ Microchaetaceae cultures } \\
\hline Microchaete sp. ${ }^{\mathrm{d}, \mathrm{f}}$ & PCC 7126 & - & - & + & ++ & - & - \\
\hline \multicolumn{8}{|l|}{ Tolypothrichaceae cultures } \\
\hline Tolypothrix tenuis $\mathrm{d}, \mathrm{f}$ & PCC 7101 & - & - & ++ & + & - & - \\
\hline
\end{tabular}

${ }^{a}$ Bauersachs et al. (2009a). ${ }^{b}$ Bauersachs et al. (2017). ${ }^{c}$ Wörmer et al. (2012). ${ }^{d}$ Gambacorta et al. (1998). ${ }^{e}$ Soriente et al. (1993). ${ }^{\mathrm{f}}$ These species also contain HGs other than the six HGs targeted in this study. 
Table 2. Analysis of HGs in Baltic sediments by Orbitrap MS. Key: ++- dominant $(>25 \%)$; +- minor presence $(5-25 \%)$; tr. - traces $(<5 \%) ;--$ not detected. Relative abundances are based on peak areas.

\begin{tabular}{|c|c|c|c|c|c|c|c|c|c|c|c|c|}
\hline Sample & $\begin{array}{l}\text { C5 } \\
26 \text { diol }\end{array}$ & $\begin{array}{l}\text { Deoxy C6 } \\
26 \text { diol }\end{array}$ & $\begin{array}{l}\text { C6 } \\
26 \text { diol}^{*}\end{array}$ & $\begin{array}{l}\text { C6 } \\
26 \text { keto-ol }\end{array}$ & $\begin{array}{l}\text { C6 } \\
28 \text { diol }\end{array}$ & $\begin{array}{l}\text { C6 } \\
28 \text { keto-ol }\end{array}$ & $\begin{array}{l}\text { C6 } \\
28 \text { triol }\end{array}$ & $\begin{array}{l}\text { C6 } \\
28 \text { keto- } \\
\text { diol }\end{array}$ & $\begin{array}{l}\text { C6 } \\
30 \text { triol }\end{array}$ & $\begin{array}{l}\text { C6 } \\
30 \text { keto- } \\
\text { diol }\end{array}$ & $\begin{array}{l}\text { C6 } \\
32 \text { triol }\end{array}$ & $\begin{array}{l}\text { C6 } \\
32 \text { keto- } \\
\text { diol }\end{array}$ \\
\hline P435-1-4 MUC 4 & - & - & ++ & + & $\operatorname{tr}$. & tr. & ++ & + & - & - & - & - \\
\hline P435-1-4 MUC 35 & - & - & ++ & + & tr. & - & + & + & - & - & - & - \\
\hline P435-1-4 MUC 62 & - & - & ++ & + & tr. & - & ++ & + & - & - & - & - \\
\hline P435-1-4 MUC 99 & - & - & ++ & tr. & tr. & - & ++ & $\operatorname{tr}$. & - & - & - & - \\
\hline $\mathrm{GC} 1-2 \mathrm{~cm}$ & - & - & ++ & tr. & tr. & - & + & - & - & - & - & - \\
\hline GC $5-6 \mathrm{~cm}$ & - & - & ++ & tr. & tr. & - & + & - & - & - & - & - \\
\hline GC $17-18 \mathrm{~cm}$ & - & - & ++ & tr. & tr. & - & + & - & - & - & - & - \\
\hline
\end{tabular}

* Sum of two isomers.

brackish phase. This is most evident for the Ancylus Lake phase I and the middle section (ca. $230-210 \mathrm{~cm}$ ) of the Ancylus Lake phase II. Yet, at the first (ca. $250-230 \mathrm{~cm}$ ) and last part (ca. 210-193 cm) of the Ancylus Lake transitional phase II, the HG distribution is more similar to the one observed in the brackish phase (Fig. 4b). This is also evident from the PCA analysis with more negative values for PC1 and PC2 at those depths (Figs. 4b and 5b). The AL-LS transition did not happen instantly (Borgendahl and Westman, 2007; Emeis et al., 1998; Gustafsson and Westman, 2002; Hyvarinen, 1984), and the sediment intervals showing a brackishlike distribution of the HGs probably correspond to weak pulses of marine water that might have occasionally entered the basin already during the Ancylus Lake transitional phase II and consequently influenced the overall distribution of the HGs (Fig. 4b). This final stage of this transition is also evident from the lithology and TOC profile (Fig. 3c).

When the Baltic evolved from a freshwater lake into a brackish semi-enclosed basin, it experienced an increase in salinity from fresh to values of 10-15\%o (Gustafsson and Westman, 2002). The observed changes in the HG distribution over the AL-LS transition suggest that this change from freshwater to brackish resulted in a different cyanobacterial species composition and hence a different HG distribution. Indeed, several freshwater species have been found to contain a HG distribution dominated by the $\mathrm{C}_{28}$ diol (Table 1), including Cyanospira rippkae (Soriente et al., 1993), Tolypothrix tenuis (Gambacorta et al., 1998) and Aphanizomenon aphanizomenoides (Wörmer et al., 2012), although we emphasize that we did not analyze $\mathrm{HGs}$ with $\mathrm{C}_{28+}$ alkyl chains for this stage and, therefore, cannot exclude the contributions of cyanobacteria producing such extended HGs. Alternatively, an increased influx of soil organic matter during the Ancylus Lake phase could be responsible for the distributional HG changes. However, since HG lipids contain an attached sugar moiety, we feel it is unlikely that HGs produced in soil will make it to the sediments of the Baltic Sea since they would be exposed extensively to oxygen during transport and only relatively stable components such as lignin, wax lipids, and branched glycerol dialkyl glycerol tetraethers (GDGTs) will likely survive this transport to the middle of the Baltic Sea where our core was taken.

For Nodularia spumigena, the most abundant heterocystous cyanobacterium in the present Baltic, its basic physiological features, such as growth, production of the toxin nodularin and differentiation of heterocysts are substantially affected at extreme salinities (Mazur-Marzec et al., 2005; Moisander et al., 2002). This is thought to be the predominant reason why Nodularia blooms only occur within a certain salinity range (i.e., 7-18\%o) in nitrogen-deficient waters (Mazur-Marzec et al., 2005). This would imply that during the Ancylus Lake phase, the low salinity was limiting the growth of Nodularia sp. Other heterocystous cyanobacteria such as Anabaena and Aphanizomenon may be better adapted to freshwater conditions.

\subsubsection{Yoldia Sea sediments}

A high variability in the $\mathrm{HG}$ distribution is also observed for the Yoldia Sea sediments (Figs. $4 \mathrm{~b}$ and $5 \mathrm{~b}$ ). The most distinct feature is the relatively high fractional abundance of the $\mathrm{C}_{28}$ diol $\mathrm{HG}$, which sometimes reaches $50 \%$, the highest value recorded for all sediments. The Yoldia Sea phase was a relatively short period when a connection with the sea was established and waters may have become brackish. Nevertheless, the HG distribution is not at all similar to that of the brackish phase.

\subsubsection{Does the distribution of the fossil HGs record a paleotemperature signal?}

As a consequence of the retreat of the ice sheet and the entry of sea water through the Danish straits, there was an increase in water temperature during the AL-LS transition (Björck, 1995). It is possible that this increase in water temperature could have been responsible for the changes in the HG distribution, as growth temperature has been reported to affect the distribution of the HGs in cyanobacteria belonging to the order Nostocales (Bauersachs et al., 2009a, 
2014b, 2015). Specifically, increasing temperature positively correlated with increasing relative proportions of HG diols over HG keto-ols. In our record, the ratio of diols to ketools increased from the Ancylus Lake towards the brackish phase (Fig. 4b), which would be in agreement with the higher SWTs during the brackish phase. However, when the HG proxies are used to estimate SWT based on the proxy calibrations from a lake (Eqs. 1-4), the predicted temperatures are somewhat unrealistic. For the brackish phase, the $\mathrm{HDI}_{26}$ and $\mathrm{HDI}_{28}$ values vary between $0.96-1.00$ and $0.95-1.00$, translating into an average SWT of ca. 24 and $23^{\circ} \mathrm{C}$, respectively. This is too high, even for summer temperatures when the cHABs occur (Kanoshina et al., 2003). TEX 86 -derived summer temperatures (Kabel et al., 2012; Warden et al., 2017) do not exceed $17.5^{\circ} \mathrm{C}$ (Fig. 3d). The application of the HGbased calibrations in this setting assumes that salinity has no impact since they have been established for a freshwater lake (Bauersachs et al., 2015). For the Ancylus Lake and Yoldia Sea phases, the $\mathrm{HDI}_{26}$ and $\mathrm{HDI}_{28}$ values are highly variable and range between $0.52-1.00$ and $0.00-0.99$, translating into average SWTs of ca. 20 and $17^{\circ} \mathrm{C}$, respectively. This is lower than observed for the brackish phase but also seems too high. Apparently, cyanobacterial species composition exerts an important control on the HG distribution in such a way that the HGs are not able to predict accurate temperatures in the brackish-freshwater system of the Baltic. Cultivation experiments with HG-producing strains isolated from the Baltic Sea (see Table 1) at varying temperatures may improve the HG paleo-thermometry of Baltic Sea sediments.

\subsection{The abundance of HGs}

\subsubsection{Is HG abundance a good measure for cHABs and anoxic events?}

In the Baltic the occurrence of summer cHABs has intensified since the 1950s (Kabel et al., 2012; Poutanen and Nikkilä, 2001). Yet, due to the spatial patchiness and interannual variability, it has proven difficult to recognize a clear trend in the cHABs on the scale of the entire Baltic (Finni et al., 2001; Kahru and Elmgren, 2014; Pitarch et al., 2016; Wasmund and Uhlig, 2003). However, the general interest in these events has led to intensified research (see Finni et al., 2001; Kahru and Elmgren, 2014; Kutser et al., 2006 among others) and also led to the establishment of the Baltic Marine Environment Protection Commission (HELCOM) in 1992 to monitor this phenomenon. Disparate indices and parameters have been employed to describe and quantify cHABs over time and were applied in the different areas of the Baltic which are biogeochemically heterogeneous and display distinct seasonal dynamics (Kahru, 1997; Kahru et al., 2007; Kahru and Elmgren, 2014; Kononen, 1992; Kutser et al., 2006; Pitarch et al., 2016; Wasmund and Uhlig, 2003). The methods employed and the frequency of the sampling campaigns have improved in the recent past, reducing the inac- curacy associated with previous sampling methods and measurements (Hansson and Öberg, 2016; Kahru, 1997; Kahru and Elmgren, 2014; Wasmund and Uhlig, 2003). However, intrinsic limitations of the techniques in use may still cause difficulties when comparing measurements from different years, even within the same time series (Finni et al., 2001; Kahru, 1997; Kahru and Elmgren, 2014).

Here, the HG abundance over the past $\sim 30$ years (i.e., 2012-1979 of the MoWP), recorded within the first $\sim 7 \mathrm{~cm}$ of the MUC, is discussed in comparison with a time series of the cHABs episodes relative to the Eastern Gotland Basin (Fig. 6), whose intensity is expressed as the frequency of cyanobacteria accumulation (FCA) (Kahru and Elmgren, 2014). FCA is determined by ocean color satellite data and expresses the frequency of the occurrence of cHABs in July-August using $1 \mathrm{~km}^{2}$ pixels (Kahru et al., 2007). Kahru and Elmgren (2014) reported prominent cHABs in the early 1980s, in the period 1990-1996 and again from 1999 until 2008, with the interval 2005-2008 recording the highest FCA percentages with relevant interannual changes of the areal extent (Kahru, 1997; Kahru et al., 1994, 2007; Kahru and Elmgren, 2014). The HG lipid biomarker abundance profile from our sampling site was overall in reasonable agreement with the FCA measurements (Fig. 6). However, it failed to record the intense cHABs of the early 1980s, and there is a mismatch of 1 or 2 years in recording the start of the strong cHABs recorded at the end of the same decade (Kahru and Elmgren, 2014). Furthermore, this comparison is complicated by a certain degree of uncertainty in the age model of the sedimentary record. Moreover, the intrinsic temporal and spatial variability in the cHABs in the modern Baltic Sea, together with the difficulties encountered in an attempt of creating a consistent long time series that combines FCA data from multiple satellite sensors, may provide an explanation for the discrepancies observed (Kahru and Elmgren, 2014; Wasmund and Uhlig, 2003).

We observed multiple peaks of the $\mathrm{HG}$ abundance in the MoWP section of the MUC core $(\leq 11 \mathrm{~cm}$ depth), which reached $\sim 50-150$ r.u. gTOC $^{-1}$. Below this in the LIA section, the HG abundance declined sharply to < 10 r.u.gTOC ${ }^{-1}$ (Fig. 3a). This decline may be expected given that the MoWP is characterized by higher summer surface temperature (Fig. 3d), increased organic matter deposition and more frequent anoxic events than the LIA phase (Kabel et al., 2012), all being conditions that lead to increased cHABs. Furthermore, the cooler LIA experienced more oxygenated bottom water, which may have affected HG preservation (see also below). However, a substantially increased HG abundance was not observed below the LIA in the MWP section of the MUC core (Fig. 3a). Similar to the MoWP period, the MWP was characterized by higher summer temperatures (Fig. 3d) and increased stratification of the water column that would favor bottom anoxia and, presumably, the occurrence of cHABs. The top of the GC also records the LIA-MWP transition (Fig. 3). Here, the HG 


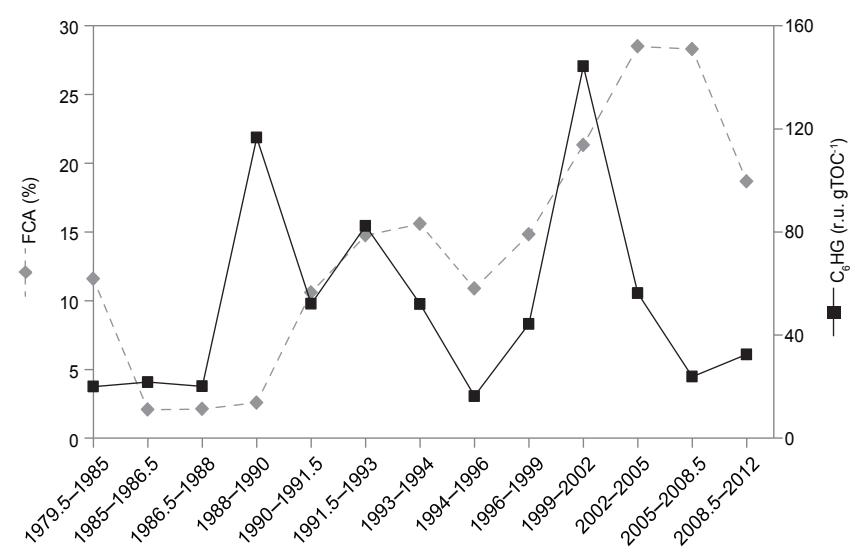

Figure 6. Abundance of heterocyst glycolipids (HGs) in the Baltic Sea over the period 1977-2012 (from MUC) compared with the fractional cyanobacteria accumulation (FCA, \%) from the time period 1979-2012, as reported by Kahru et al. (2014).

abundance reached $\sim 10-18$ r.u. gTOC ${ }^{-1}$ at $<30 \mathrm{~cm}$ depth, which is up to 4 times higher than the HG abundance observed in the MUC for the same period. This discrepancy between the HGs records in the two related cores is puzzling. After the MWP, HG abundance declined to $\leq 5$ r.u. gTOC $^{-1}$ during the remaining part of the brackish phase, as recorded in the GC (Fig. 3a), with only a minor increase in the HG abundance during the periods when summer temperature was higher and the Baltic Sea was stratified, resulting in bottom water anoxia (Fig. 3; e.g., during the Holocene Thermal Maximum).

Based on these data from the Baltic Sea, it is not possible to confidently couple the HG abundance record directly with $\mathrm{cHAB}$ occurrences and anoxic events in the past. Several factors are thought to affect this relationship. Firstly, it is possible that the occurrence of cHABs varied over time. In the shallow part of both sediment cores, HG abundance was generally high, but it started declining with increasing depth, independently of other factors (Fig. 3). This might suggest that cHABs were less common and intense in the past brackish Baltic Sea, even at times of warmer and more stratified conditions. Secondly, the succession of oxic and anoxic bottom water conditions may impact the preservation efficiency of HGs. Such successions took place in the Baltic Sea during the entire Holocene as is evident from the alternation of dark-laminated with light-homogeneous sections in the sedimentary record (Kabel et al., 2012). In the shallow part of both sediment cores, the high abundance of HGs coincided with dark-laminated sediment phases; low HGs, by contrast, co-occurred with light-homogeneous phases. In contrast, in the deeper part of the section this correspondence was lost. Finally, the generally declining trend in the HG absolute abundance in the shallow sediments might also be due to the anaerobic breakdown of the HGs. A decline in lipid biomarkers with depth has been documented before in anoxic
Black Sea surface sediments (Sun and Wakeham, 1994). This process would be seemingly in contrast with previous indications of a high preservation potential of the HGs in ancient marine and lacustrine anoxic sediments (Bauersachs et al., 2010), but it should be realized that even in the older Baltic Sea sediments, HGs are still detected. Apparently, even if diagenesis occurs, it does not result in the complete destruction of HGs.

The HG results seem to partly contrast an earlier study that, based on fossil pigment records, suggested that cHABs have been recurring simultaneously with the mid-Holocene anoxic events (Funkey et al., 2014). However, this study used carotenoids (i.e., zeaxanthin and echinenone) that are not entirely specific to cyanobacteria and are certainly not limited to nitrogen-fixing cyanobacteria, as opposed to the highly specific HGs that were used here. For example, zeaxanthin is also produced by Synechococcus, the dominating unicellular cyanobacterial species in the Baltic Sea (Celepli et al., 2017). Furthermore, in this environment of highly variable sediment redox conditions, the effect of diagenesis should be considered. Carotenoids are amongst the most unstable organic biomarkers because of their very labile conjugated system of double bonds. Changes in redox conditions of bottom and sediment pore waters will thus have a major effect on the concentration of carotenoids, and this may explain the enhanced concentration of carotenoids in the mid-Holocene TOC-enriched sections (Funkey et al., 2014).

\subsubsection{Changing abundance of the HGs over the AL-LS transition}

The general down-core decrease in the HG abundance throughout the brackish phase is continued into the Ancylus Lake and Yoldia Sea phases, where the HG abundance is at least an order of magnitude lower than in the first part of the brackish phase (Fig. 3a). The lower HG abundance in the Ancylus Lake and Yoldia Sea phases, relative to the brackish phase, could indicate that $\mathrm{N}_{2}$-fixing cyanobacteria were much less abundant during this freshwater phase. Indeed, further evidence for a lower abundance of diazotrophic phytoplankton during the Ancylus Lake and Yoldia Sea phases comes from the record of $\delta^{15} \mathrm{~N}$ values (Fig. 3b). During these phases the $\delta^{15} \mathrm{~N}$ values are $4-6 \%$, indicating that most of the phytoplankton community was relying on ammonium or nitrate as nitrogen sources rather than atmospheric nitrogen (Bauersachs et al., 2009b; Emerson and Hedges, 2008). When other forms of nitrogen are abundant the energetically expensive $\mathrm{N}_{2}$ fixation becomes disadvantageous (Arrigo, 2005; Capone et al., 2005; Karl et al., 1997). At the start of the LS phase, $\delta^{15} \mathrm{~N}$ values drop to $1-3 \%$ (Fig. 3b), a range expected when $\mathrm{N}_{2}$-fixing cyanobacteria contribute substantially to primary production (Bauersachs et al., 2009b; Rejmánková et al., 2004; Zakrisson et al., 2014), and remained in this range. 
As discussed above, the salinity change from a freshwater lake to a brackish sea may have had a significant effect on the heterocystous cyanobacterial composition in the Baltic. This environmental change may have also been a cause of the increased abundance of heterocystous cyanobacteria. Another environmental factor change that could have promoted increased blooming of heterocystous cyanobacteria is the increase in water temperature over the AL-LS transition (Björck, 1995). Temperature is a crucial factor influencing the growth rate and other metabolic features of free-living heterocystous cyanobacteria (Bauersachs et al., 2014b; Kabel et al., 2012; Mazur-Marzec et al., 2005; Staal et al., 2003). In the modern Baltic Sea, a minimum temperature of $16^{\circ} \mathrm{C}$ is considered essential to initiate cHABs during summer when other crucial factors like a low DIN/DIP ratio, calm winds and high irradiance occur simultaneously (Kanoshina et al., 2003; Kononen, 1992; Kononen et al., 1996; Paerl, 2008; Wasmund, 1997).

It should also be noted, however, that the homogeneous appearance of the sediments and the much reduced TOC content (Fig. 3c) reveal that the water column was generally well mixed and oxygenated during the Ancylus Lake and Yoldia Sea phases, resulting in a higher degradation of organic matter (including HGs) in settling particles and surface sediments. To compensate for this effect, all HG concentrations were normalized to TOC content (Fig. 3a). However, it is known that oxic conditions in the sediment result in a decreased preservation of biomarkers relative to TOC (see Sinninghe Damsté et al., 2002). This may also explain in part the lower HG abundance in the Ancylus Lake and Yoldia Sea than in the brackish phase. However, it is noteworthy that no substantial change in the concentration of HGs is observed during the brackish phase when bottom water conditions changed from oxic to anoxic (Fig. 3). This suggest that the normalization to TOC content is an effective way to compensate for changing redox conditions of bottom and pore waters. The effect of oxic degradation is probably also not responsible for substantial changes in the distribution of the HGs since they are structurally similar and all contain a relatively labile glycosidic bond, so there is no reason to assume that one HG will degrade faster than another.

\section{Conclusions}

The distribution of the six analyzed $\mathrm{C}_{6}$ HGs in the Baltic sediments from the brackish phases were closely related to those of cultivated heterocystous cyanobacteria of the family Nostocaceae. The record also shows that the HG distribution has remained stable since the Baltic turned into a brackish semi-enclosed basin $\sim 7200$ cal. yr BP. During the freshwater phase of the Baltic (i.e., the Ancylus Lake phase) and an earlier brackish period (the Yoldia Sea phase), the distribution of the HGs was quite distinct but varied much more than in the subsequent brackish phase. This suggests that the cyanobacterial community adjusted to the different environmental conditions in the basin over this transition. We found that the abundance of HGs dropped substantially down-core, possibly either due to a decrease in the cHABs or during oxic degradation during deposition, resulting in the partial destruction of the HGs.

In conclusion, it is likely that both salinity and temperature have influenced the abundance and composition of the heterocystous cyanobacterial community of the Baltic since the last deglaciation. The effects of salinity on the synthesis and distribution of HGs would need to be investigated in controlled conditions to be confirmed, as has been partially done already in the case of temperature. Further studies are also needed to extend the range of heterocystous cyanobacteria species in culture that have been investigated for their HG content.

Data availability. The data will be made available in the Pangaea database (https://www.pangaea.de).

\section{The Supplement related to this article is available online at https://doi.org/10.5194/bg-14-5789-2017-supplement.}

Competing interests. The authors declare that they have no conflict of interest.

Acknowledgements. We thank the captain and the crew of the R/V Prof. Albrecht Penck (cruise July 2009), and of the R/V Poseidon (cruise June 2012) for their support and assistance in the sampling. We thank Mati Kahru for providing FCA data and three anonymous referees and Dan Conley for helpful suggestions on an earlier draft of this paper. This project was funded by a grant to Jaap S. Sinninghe Damsté from the Darwin Center for Biogeosciences (project no. 3012). The work was further supported by funding from the Netherlands Earth System Science Center (NESSC) through a Gravitation grant (NWO 024.002.001) from the Dutch Ministry for Education, Culture and Science to Jaap S. Sinninghe Damsté.

Edited by: Clare Woulds

Reviewed by: three anonymous referees

\section{References}

Adams, D. G.: Heterocyst formation in cyanobacteria, Curr. Opin. Microbiol., 3, 618-624, 2000.

Andrén, E., Andrén, T., and Kunzendorf, H.: Holocene history of the Baltic Sea as a background for assessing records of human impact in the sediments of the Gotland Basin, Holocene, 10, 687702, https://doi.org/10.1191/09596830094944, 2000. 
Andrén, T., Björck, S., Andrén, E., Conley, D. J., Zillén, L., and Anjar, J.: The Development of the Baltic Sea Basin During the Last $130 \mathrm{ka}$, in: The Baltic Sea Basin, chap. 4, edited by: Harff, J., Björck, S., and Hoth, P., Springer, Berlin Heidelberg, Germany, 75-97, 2011.

Arrigo, K. R.: Marine microorganisms and global nutrient cycles, Nature, 437, 349-355, https://doi.org/10.1038/nature04158, 2005.

Bale, N. J., Hopmans, E. C., Zell, C., Lima Sobrinho, R., Kim, J. H., Sinninghe Damsté, J. S., Villareal, T. A., and Schouten, S.: Long chain glycolipids with pentose head groups as biomarkers for marine endosymbiotic heterocystous cyanobacteria, Org. Geochem., 81, 1-7, https://doi.org/10.1016/j.orggeochem.2015.01.004, 2015.

Bale, N. J., Hopmans, E. C., Schoon, P. L., de Kluijver, A., Downing, J. A., Middelburg, J. J., Sinninghe Damsté, J. S., and Schouten, S.: Impact of trophic state on the distribution of intact polar lipids in surface waters of lakes, Limnol. Oceanogr., 61, 1065-1077, https://doi.org/10.1002/lno.10274, 2016.

Bale, N. J., Villareal, T. A., Hopmans, E. C., Brussaard, C. P. D., Besseling, M., Dorhout, D., Sinninghe Damsté, J. S., and Schouten, S.: $\mathrm{C}_{5}$ glycolipids of heterocystous cyanobacteria track symbiont abundance in the diatom Hemiaulus hauckii across the tropical north Atlantic, Biogeosciences Discuss., https://doi.org/10.5194/bg-2017-300, in review, 2017.

Bauersachs, T., Compaore, J., Hopmans, E. C., Stal, L. J., Schouten, S., and Sinninghe Damsté, J. S.: Distribution of heterocyst glycolipids in cyanobacteria, Phytochemistry, 70, 20342039, https://doi.org/10.1016/j.phytochem.2009.08.014, 2009a.

Bauersachs, T., Schouten, S., Compaoré, J., Wollenzien, U., Stal, L. J., and Sinninghe Damsté, J. S.: Nitrogen isotopic fractionation associated with growth on dinitrogen gas and nitrate by cyanobacteria, Limnol. Oceanogr., 54, 1403-1411, https://doi.org/10.4319/lo.2009.54.4.1403, 2009b.

Bauersachs, T., Hopmans, E. C., Compaore, J., Stal, L. J., Schouten, S., and Sinninghe Damsté, J. S.: Rapid analysis of long-chain glycolipids in heterocystous cyanobacteria using high-performance liquid chromatography coupled to electrospray ionization tandem mass spectrometry, Rapid. Commun. Mass Sp., 23, 1387-1394, https://doi.org/10.1002/rcm.4009, 2009c.

Bauersachs, T., Speelman, E. N., Hopmans, E. C., Reichart, G.J., Schouten, S., and Sinninghe Damsté, J. S.: Fossilized glycolipids reveal past oceanic $\mathrm{N}_{2}$ fixation by heterocystous cyanobacteria, P. Natl. Acad. Sci. USA, 107, 19190-19194, https://doi.org/10.1073/pnas.1007526107, 2010.

Bauersachs, T., Compaore, J., Severin, I., Hopmans, E. C., Schouten, S., Stal, L. J., and Sinninghe Damsté, J. S.: Diazotrophic microbial community of coastal microbial mats of the southern North Sea, Geobiology, 9, 349-359, https://doi.org/10.1111/j.1472-4669.2011.00280.x, 2011.

Bauersachs, T., Miller, S. R., van der Meer, M. T. J., Hopmans, E. C., Schouten, S., and Sinninghe Damsté, J. S.: Distribution of long chain heterocyst glycolipids in cultures of the thermophilic cyanobacterium Mastigocladus laminosus and a hot spring microbial mat, Org. Geochem., 56, 19-24, https://doi.org/10.1016/j.orggeochem.2012.11.013, 2013.

Bauersachs, T., Mudimu, O., Schulz, R., and Schwark, L.: Distribution of long chain heterocyst glycolipids in $\mathrm{N}_{2}$-fixing cyanobac- teria of the order Stigonematales, Phytochemistry, 98, 145-150, https://doi.org/10.1016/j.phytochem.2013.11.007, 2014a.

Bauersachs, T., Stal, L. J., Grego, M., and Schwark, L.: Temperature induced changes in the heterocyst glycolipid composition of $\mathrm{N}_{2}$ fixing heterocystous cyanobacteria, Org. Geochem., 69, 98-105, https://doi.org/10.1016/j.orggeochem.2014.02.006, 2014b.

Bauersachs, T., Rochelmeier, J., and Schwark, L.: Seasonal lake surface water temperature trends reflected by heterocyst glycolipidbased molecular thermometers, Biogeosciences, 12, 3741-3751, https://doi.org/10.5194/bg-12-3741-2015, 2015.

Bauersachs, T., Talbot, H. M., Sidgwick, F., Sivonen, K., and Schwark, L.: Lipid biomarker signatures as tracers for harmful cyanobacterial blooms in the Baltic Sea, PLoS One, 12, e0186360, https://doi.org/10.1371/journal.pone.0186360, 2017.

Bianchi, T. S., Engelhaupt, E., Westman, P., Andrén, T., Rolff, C., and Elmgren, R.: Cyanobacterial blooms in the Baltic Sea: natural or human-induced?, Limnol. Oceanogr., 45, 716-726, https://doi.org/10.4319/lo.2000.45.3.0716, 2000.

Björck, S.: A review of the history of the Baltic Sea, 13.08.0 ka BP, Quatern. Int., 27, 19-40, https://doi.org/10.1016/10406182(94)00057-C, 1995.

Borgendahl, J. and Westman, P.: Cyanobacteria as a trigger for increased primary productivity during sapropel formation in the Baltic Sea - a study of the Ancylus/Litorina transition, J. Paleolimnol., 38, 1-12, https://doi.org/10.1007/s10933-006-9055-0, 2007.

Bryce, T. A., Welti, D., Walsby, A. E., and Nichols, B. W.: Monohexoside derivatives of long-chain polyhydroxy alcohols; a novel class of glycolipid specific to heterocystous algae, Phytochemistry, 11, 295-302, https://doi.org/10.1016/S00319422(00)90006-2, 1972.

Capone, D. G., Burns, J. A., Montoya, J. P., Subramaniam, A., Mahaffey, C., Gunderson, T., Michaels, A. F., and Carpenter, E. J.: Nitrogen fixation by Trichodesmium spp.: An important source of new nitrogen to the tropical and subtropical North Atlantic Ocean, Global Biogeochem. Cy., 19, GB2024, https://doi.org/10.1029/2004GB002331, 2005.

Celepli, N., Sundh, J., Ekman, M., Dupont, C. L., Yooseph, S., Bergman, B., and Ininbergs, K.: Meta-omic analyses of Baltic Sea cyanobacteria: diversity, community structure and salt acclimation, Environ. Microbiol., 19, 673-686, https://doi.org/10.1111/1462-2920.13592, 2017.

Emeis, K.-C., Neumann, T., Endler, R., Struck, U., Kunzendorf, H., and Christiansen, C.: Geochemical records of sediments in the Eastern Gotland Basin - products of sediment dynamics in a not-so-stagnant anoxic basin?, Appl. Geochem., 13, 349-358, https://doi.org/10.1016/S0883-2927(97)00104-2, 1998.

Emerson, S. and Hedges, J.: Chemical Oceanography and the Marine Carbon Cycle, Cambridge University Press, Cambridge, UK, 2008.

Finni, T., Kononen, K., Olsonen, R., and Wallström, K.: The history of cyanobacterial blooms in the Baltic Sea, Ambio, 30, 172-178, https://doi.org/10.1579/0044-7447-30.4.172, 2001.

Fritz, S. C.: Lake development and limnological response to prehistoric and historic land-use in Diss, Norfolk, UK, J. Ecol., 77, 182-202, https://doi.org/10.2307/2260924, 1989.

Funkey, C. P., Conley, D. J., Reuss, N. S., Humborg, C., Jilbert, T., and Slomp, C. P.: Hypoxia sustains cyanobacteria 
blooms in the Baltic Sea, Environ. Sci. Technol., 48, 2598-2602, https://doi.org/10.1021/es404395a, 2014.

Gambacorta, A., Soriente, A., Trincone, A., and Sodano, G.: Biosynthesis of the heterocyst glycolipids in the cyanobacterium Anabaena cylindrica, Phytochemistry, 39, 771-774, https://doi.org/10.1016/0031-9422(95)00007-T, 1995.

Gambacorta, A., Pagnotta, E., Romano, I., Sodano, G., and Trincone, A.: Heterocyst glycolipids from nitrogen-fixing cyanobacteria other than Nostocaceae, Phtytochemistry, 48, 801-205, 1998.

Gustafsson, B. G. and Westman, P.: On the causes for salinity variations in the Baltic Sea during the last 8500 years, Paleoceanography, 17, 1040-1, https://doi.org/10.1029/2000PA000572, 2002.

Hajdu, S., Höglander, H., and Larsson, U.: Phytoplankton vertical distributions and composition in Baltic Sea cyanobacterial blooms, Harmful Algae, 6, 189-205, https://doi.org/10.1016/j.hal.2006.07.006, 2007.

Hällfors, G.: Checklist of Baltic Sea Phytoplankton Species (including some heterotrophic protistan groups), Baltic Sea Environment Proceedings, 95, 1-208, 2004.

Hansson, M. and Öberg, J.: Cyanobacterial blooms in the Baltic Sea in 2010, HELCOM Baltic Sea Environ. Fact Sheets, available at: http://www.helcom.fi/ baltic-sea-trends/environment-fact-sheets/eutrophication/ cyanobacterial-blooms-in-the-baltic-sea (last access: 22 January 2017), 2010.

Hyvarinen, H.: The Mastogloia Stage in Baltic Sea history: diatom evidence from southern Finland, B. Geol. Soc. Finland, 56, 99116,1984

Jensen, J. B., Bennike, O., Witkowski, A., Lemke, W., and Kuijpers, A.: Early Holocene history of the southwestern Baltic Sea: the Ancylus Lake stage, Boreas, 28, 437-453, https://doi.org/10.1111/j.1502-3885.1999.tb00233.x, 1999.

Kabel, K., Moros, M., Porsche, C., Neumann, T., Adolphi, F., Andersen, T. J., Siegel, H., Gerth, M., Leipe, T., Jansen, E., Damsté, S., and S, J.: Impact of climate change on the Baltic Sea ecosystem over the past 1000 years, Nat. Clim. Change, 2, 871-874, https://doi.org/10.1038/nclimate1595, 2012.

Kahru, M.: Monitoring Algal Blooms: New Techniques for Detecting Large-Scale Environmental Change, Springer, Berlin, Germany, New York, USA, 1997.

Kahru, M. and Elmgren, R.: Multidecadal time series of satellitedetected accumulations of cyanobacteria in the Baltic Sea, Biogeosciences, 11, 3619-3633, https://doi.org/10.5194/bg-113619-2014, 2014.

Kahru, M., Horstmann, U., and Rud, O.: Satellite detection of increased cyanobacteria blooms in the Baltic Sea: natural fluctuation or ecosystem change?, Ambio, 23, 469-472, 1994

Kahru, M., Savchuk, O. P., and Elmgren, R.: Satellite measurements of cyanobacterial bloom frequency in the Baltic Sea: interannual and spatial variability, Mar Ecol.-Prog. Ser., 343, 15-23, https://doi.org/10.3354/meps06943, 2007.

Kanoshina, I., Lips, U., and Leppänen, J.-M.: The influence of weather conditions (temperature and wind) on cyanobacterial bloom development in the Gulf of Finland (Baltic Sea), Harmful Algae, 2, 29-41, https://doi.org/10.1016/S1568-9883(02)000859, 2003.

Karjalainen, M., Engström-Ost, J., Korpinen, S., Peltonen, H., Pääkkönen, J.-P., Rönkkönen, S., Suikkanen, S., and Vi- itasalo, M.: Ecosystem consequences of cyanobacteria in the northern Baltic Sea, Ambio, 36, 195-202, 2007.

Karl, D., Letelier, R., Tupas, L., Dore, J., Christian, J., and Hebel, D.: The role of nitrogen fixation in biogeochemical cycling in the subtropical North Pacific Ocean, Nature, 388, 533538, https://doi.org/10.1038/41474, 1997.

Kononen, K.: Dynamics of the Toxic Cyanobacterial Blooms in the Baltic Sea, PhD thesis, Finnish Marine Reasearch, University of Helsinki, Helsinki, Finland, 1992.

Kononen, K., Kuparinen, J., Kalervo, M., Laanemets, J., Pavelson, J., and Nõmmann, S.: Initiation of cyanobacterial blooms in a frontal region at the entrance to the Gulf of Finland, Baltic Sea., Limnol. Oceanogr., 41, 98-112, https://doi.org/10.4319/lo.1996.41.1.0098, 1996.

Kutser, T., Metsamaa, L., Strömbeck, N., and Vahtmäe, E.: Monitoring cyanobacterial blooms by satellite remote sensing, Estuar. Coast. Shelf S., 67, 303-312, https://doi.org/10.1016/j.ecss.2005.11.024, 2006.

Lambein, F. and Wolk, C. P.: Structural studies on the glycolipids from the envelope of the heterocyst of Anabaena cylindrica, Biochemistry, 12, 791-798, 1973.

Mazur-Marzec, H., Żeglińska, L., and Pliński, M.: The effect of salinity on the growth, toxin production, and morphology of Nodularia spumigena isolated from the Gulf of Gdańsk, southern Baltic Sea, J. Appl. Phycol., 17, 171-179, https://doi.org/10.1007/s10811-005-5767-1, 2005.

McGowan, S., Britton, G., Haworth, E., and Moss, B.: Ancient blue-green blooms, Limnol. Oceanogr., 44, 436-439, https://doi.org/10.4319/lo.1999.44.2.0436, 1999.

Moisander, P. H., McClinton, E., and Paerl, H. W.: Salinity effects on growth, photosynthetic parameters, and nitrogenase activity in estuarine planktonic cyanobacteria, Microb. Ecol., 43, 432-442, https://doi.org/10.1007/s00248-001-1044-2, 2002.

Moore, E. K., Hopmans, E. C., Rijpstra, W. I. C., Villanueva, L., Dedysh, S. N., Kulichevskaya, I. S., Wienk, H., Schoutsen, F., and Sinninghe Damsté, J. S.: Novel mono-, di, and trimethylornithine membrane lipids in northern wetland Planctomycetes, Appl. Environ. Microb., 79, 6874-6884, https://doi.org/10.1128/AEM.02169-13, 2013.

Murry, M. A. and Wolk, C. P.: Evidence that the barrier to the penetration of oxygen into heterocysts depends upon two layers of the cell envelope, Arch. Microbiol., 151, 469-474, https://doi.org/10.1007/BF00454860, 1989.

Nichols, B. W. and Wood, B. J. B.: New glycolipid specific to nitrogen-fixing blue-green algae, Nature, 217, 767-768, https://doi.org/10.1038/217767a0, 1968.

Paerl, H.: Nutrient and other environmental controls of harmful cyanobacterial blooms along the freshwater-marine continuum, in: Cyanobacterial Harmful Algal Blooms: State of the Science and Research Needs. Advances in Experimental Medicine and Biology, vol. 619, edited by: Hudnell, H. K., Springer, New York, NY, USA, 217-237, https://doi.org/10.1007/978-0-387-758657_10, 2008.

Paerl, H. W.: Nuisance phytoplankton blooms in coastal, estuarine, and inland waters1, Limnol. Oceanogr., 33, 823-843, https://doi.org/10.4319/lo.1988.33.4part2.0823, 1988.

Paerl, H. W. and Huisman, J.: Climate change: a catalyst for global expansion of harmful cyanobacterial blooms, 
Env. Microbiol. Rep., 1, 27-37, https://doi.org/10.1111/j.17582229.2008.00004.x, 2009.

Paerl, H. W., Hall, N. S., and Calandrino, E. S.: Controlling harmful cyanobacterial blooms in a world experiencing anthropogenic and climatic-induced change, Sci. Total Environ., 409, 17391745, https://doi.org/10.1016/j.scitotenv.2011.02.001, 2011.

Pitarch, J., Volpe, G., Colella, S., Krasemann, H., and Santoleri, R.: Remote sensing of chlorophyll in the Baltic Sea at basin scale from 1997 to 2012 using merged multi-sensor data, Ocean Sci., 12, 379-389, https://doi.org/10.5194/os-12-379-2016, 2016.

Ploug, H.: Cyanobacterial surface blooms formed by Aphanizomenon sp., and Nodularia spumigena in the Baltic Sea: small-scale fluxes, $\mathrm{pH}$, and oxygen microenvironments., Limnol. Oceanogr., 53, 914-921, https://doi.org/10.4319/1o.2008.53.3.0914, 2008.

Poutanen, E. L. and Nikkilä, K.: Carotenoid pigments as tracers of cyanobacterial blooms in recent and postglacial sediments of the Baltic Sea, Ambio, 30, 179-183, 2001.

Rejmánková, E., Komárková, J., and Rejmánek, M.: $\delta^{15} \mathrm{~N}$ as an indicator of $\mathrm{N}_{2}$-fixation by cyanobacterial mats in tropical marshes, Biogeochemistry, 67, 353-368, https://doi.org/10.1023/B:BIOG.0000015790.28584.ed, 2004.

Rippka, R., Deruelles, J., Waterbury, J. B., Herdman, M., and Stanier, R. Y.: Generic assignments, strain histories and properties of pure cultures of cyanobacteria, Microbiology, 111, 1-61, https://doi.org/10.1099/00221287-111-1-1, 1979.

Schouten, S., Villareal, T. A., Hopmans, E. C., Mets, A., Swanson, K. M., and Sinninghe Damsté, J. S.: Endosymbiotic heterocystous cyanobacteria synthesize different heterocyst glycolipids than free-living heterocystous cyanobacteria, Phytochemistry, 85, 115-21, https://doi.org/10.1016/j.phytochem.2012.09.002, 2013.

Schweger, C. E. and Hickman, M.: Holocene paleohydrology of central Alberta: testing the general-circulation-model climate simulations, Can. J. Earth Sci., 26, 1826-1833, https://doi.org/10.1139/e89-155, 1989.

Sinninghe Damsté, J. S., Rijpstra, W. I. C., and Reichart, G.: The influence of oxic degradation on the sedimentary biomarker record. II. Evidence from Arabian Sea sediments, Geochim. Cosmochim. Ac., 66, 2737-2754, https://doi.org/10.1016/S00167037(02)00865-7, 2002.

Sivonen, K., Halinen, K., Sihvonen, L. M., Koskenniemi, K., Sinkko, H., Rantasärkkä, K., Moisander, P. H., and Lyra, C.: Bacterial diversity and function in the Baltic Sea with an emphasis on cyanobacteria, Ambio, 36, 180-185, https://doi.org/10.1579/0044-7447(2007)36[180:bdafit]2.0.co;2, 2007.

Soriente, A., Gambacorta, A., Trincone, A., Sili, C., Vincenzini, M., and Sodano, G.: Heterocyst glycolipids of the cyanobacterium Cyanospira rippkae, Phytochemistry, 33, 393-396, 1993.

Staal, M., Meysman, F. J. R., and Stal, L. J.: Temperature excludes $\mathrm{N}_{2}$ fixing heterocystous cyanobacteria in the tropical oceans, Nature, 425, 504-507, https://doi.org/10.1038/nature01999, 2003.

Stal, L. J.: Is the distribution of nitrogen-fixing cyanobacteria in the oceans related to temperature?, Environ. Microbiol., 11, 16321645, https://doi.org/10.1111/j.1758-2229.2009.00016.x, 2009.
Stipa, T.: The dynamics of the N / P ratio and stratification in a large nitrogen-limited estuary as a result of upwelling: a tendency for offshore Nodularia blooms, Hydrobiologia, 487, 219-227, https://doi.org/10.1023/A:1022990116669, 2002.

Sun, M.-Y., and Wakeham, S. G.: Molecular evidence for degradation and preservation of organic matter in the anoxic Black Sea Basin, Geochim. Cosmochim. Ac., 58, 3395-3406, https://doi.org/10.1016/0016-7037(94)90094-9, 1994.

Walsby, A. E.: The permeability of heterocysts to the gases nitrogen and oxygen, P. R. Soc. London, 226, 345-366, https://doi.org/10.1098/rspb.1985.0099, 1985.

Warden, L. A.: Paleoenvironmental Reconstructions in the Baltic Sea and Iberian Margin, PhD Thesis, University of Utrecht, Utrecht, the Netherlands, 2017.

Warden, L. Moros, M., Neumann, T., Shennan, S., Timpson, A., Manning, K., Sollai, M., Wacker, L., Perner, K., Häusler, K., Leipe, T., Zillén, L., Kotilainen, A., Jansen, E., Schneider, R. R., Oeberst, R., Arz, H., and Sinninghe Damsté, J. S.: Climate induced human demographic and cultural change in northern Europe during the mid-Holocene, Sci. Rep.-UK, 7, 15251, https://doi.org/10.1038/s41598-017-14353-5, 2017.

Wasmund, N.: Occurrence of cyanobacterial blooms in the Baltic Sea in relation to environmental conditions, Int. Rev. Hydrobiol., 82, 169-184, https://doi.org/10.1002/iroh.19970820205, 1997.

Wasmund, N. and Uhlig, S.: Phytoplankton trends in the Baltic Sea, ICES J. Mar Sci., 60, 177-186, https://doi.org/10.1016/S10543139(02)00280-1, 2003.

Whitton, B. A. and Potts, M.: Introduction to cyanobacteria, in: Ecology of Cyanobacteria. II. Their Diversity in Space and Time, chap. 1, edited by: Whitton, B. A., Springer, Berlin Heidelberg, Germany, 1-15, 2012.

Wolk, C. P.: Heterocysts, in: The Biology of Cyanobacteria, edited by: Carr, N. G., Whitton, B. A., Blackwell Scientific Publishers, Oxford, UK, 359-386, 1982.

Wörmer, L., Cires, S., Velazquez, D., Quesada, A., and Hinrichs, K.-U.: Cyanobacterial heterocyst glycolipids in cultures and environmental samples: diversity and biomarker potential, Limnol. Oceanogr., 57, 1775-1788, https://doi.org/10.4319/lo.2012.57.6.1775, 2012.

Zakrisson, A., Larsson, U., and Höglander, H.: Do Baltic Sea diazotrophic cyanobacteria take up combined nitrogen in situ?, J. Plankton Res., 36, 1368-1380, https://doi.org/10.1093/plankt/fbu053, 2014.

Zillén, L. and Conley, D. J.: Hypoxia and cyanobacteria blooms - are they really natural features of the late Holocene history of the Baltic Sea?, Biogeosciences, 7, 2567-2580, https://doi.org/10.5194/bg-7-2567-2010, 2010.

Züllig, H.: Carotenoids from plankton and photosynthetic bacteria in sediments as indicators of trophic changes in Lake Lobsigen during the last 14000 years, Hydrobiologia, 143, 315-319, https://doi.org/10.1007/BF00026676, 1986. 